\title{
NISTIR 88-3876
}

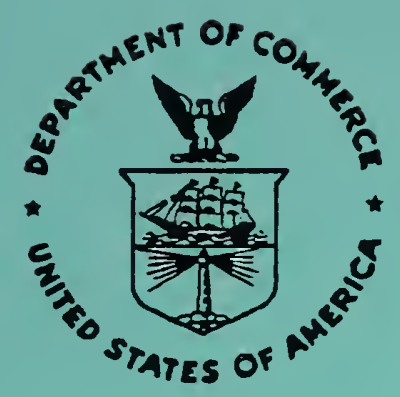

\section{An Investigation of a User-Operated Mass Calibration Package}

Randall M. Schoonover and James E. Taylor

U.S. DEPARTMENT OF COMMERCE

National Institute of Standards and Technology

(Formerly National Bureau of Standards)

National Engineering Laboratory

Center for Manufacturing Engineering

Gaithersburg, MD 20899

November 1988

Prepared for

U.S. DEPARTMENT OF COMMERCE

National Institute of Standards and Technology

(Formerly National Bureau of Standards)

Office of Weights and Measures

Gaithersburg, MD 20899

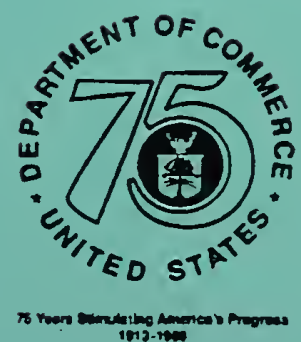





\title{
An Investigation of a User-Operated Mass Calibration Package
}

Randall M. Schoonover and James E. Taylor

U.S. DEPARTMENT OF COMMERCE

National Institute of Standards and Technology

(Formerly National Bureau of Standards)

National Engineering Laboratory

Center for Manufacturing Engineering

Gaithersburg, MD 20899

November 1988

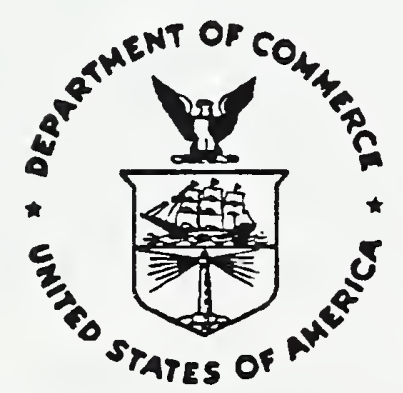

Prepared for

U.S. DEPARTMENT OF COMMERCE

National Institute of Standards and Technology

(Formerly National Bureau of Standards)

Office of Weights and Measures

Gaithersburg, MD 20899
National Bureau of Standards became the National Institute of Standards and Technology on August 23, 1988, when the Omnibus Trade and Competitiveness Act was signed. NIST retains all NBS functions. Its new programs will encourage improved use of technology by U.S. industry.

\section{U.S. DEPARTMENT OF COMMERCE \\ C. William Verity, Secretary}

\author{
NATIONAL INSTITUTE OF STANDARDS \\ AND TECHNOLOGY \\ Ernest Ambler, Director
}


An Investigation of a User-Operated Mass Calibration Package

by

Randall M. Schoonover and James E. Taylor

\begin{abstract}
Reported here are the results of two round-robin mass measurement programs. The first round-robin elucidated the many technical problems that required solutions before successful mass calibrations could be performed in all of the participant laboratories. This report details the technical innovations incorporated in the second round-robin, i.e., thermal conditioning of the kilogram weights, balance servo control, automatic data acquisition, the measurement of some air density parameters, and computer software and presents the results. We believe these results clearly indicate that properly instructed personnel could, in the future, successfully calibrate mass standards at locations remote from the National Institute of Standards and Technology (NIST) laboratory while maintaining the rigor necessary for certification.
\end{abstract}

\title{
Introduction
}

The process of disseminating the mass unit begins when a metrologist observes the difference between two masses by noting the force each mass exerts on a balance beam. One of the masses is the standard and embodies the mass unit, and the other is to be assigned a value relative to the standard. In practice more information is required on both objects than simply the mass of the standard. The metrologist needs additional information that characterizes both objects and, in addition, detailed knowledge of the entire calibration process.

In essence the work reported here is the application of knowledge gained from planned studies of systematic errors in the mass measurement process. Here we describe a user-operated mass calibration package whose design builds on much of the early work. We also provide data from a ten laboratory round-robin test of the package. We believe the test results support the concept of a mass calibration performed by the user and certified by the NIST.

Furthermore, we believe the concept of this package is unusual in that it contains everything necessary to perform the calibration, insure its correctness and issue a calibration report. In short, all the user provides is laboratory space, a balance of appropriate capacity and precision, and a balance operator.

\section{Philosophy}

In considering the usefulness of a user-performed mass calibration, one could compare it to the established service where the user submits mass standards to the NIST for calibration. Other than a purchase order no 
other communication is necessary between the user and the NIST. In short, the user pays a fee and the NIST provides a report of calibration. The approach we propose offers user participation in the calibration process, enhances communication and, according to most users leaves them with much more than a report of calibration. In summary, they gain confidence in the measurements they provide to their clientele as this method disseminates techniques and experience as well as the mass unit.

\section{Background}

Beginning in the early 1960's the NIST mass group became interested in the development of a solid object density scale. The thinking at that time was that the material would probably have a density lower than stainless steel and be either of single crystal in structure or a ceramic [1]. The material eventually chosen was single crystal-silicon with a density of 2.3 grams per cubic centimeter. The choice of silicon immediately posed many questions as our experience in high accuracy weighing was limited to plated brass or stainless steel laboratory mass standards. There was a concern regarding the adequacy of the air density equation used for making air buoyancy corrections. Such corrections would be unusually large when making mass comparisons between silicon and metallic weights with densities near 8 grams per cubic centimeter. The correction is almost non-existent when weighing various alloys of stainless steel. There were other concerns about weighing dissimilar materials related to surface effects, stability, thermal and electrical conductivity, etc. Interest in these matters was again renewed in 1975 by Pontius [2] and has continued until present. We have summarized all of this work in a paper published in 1986 [3]. However, the individual studies can be reviewed in detail by referring to references [2-8]. For completeness we give whatever brief descriptions are necessary as the need arises in the text of this report.

\section{Round-Robin Measurements}

In the report of our earlier round-robin measurement [7] we suggested that any future package should include the following:

- Portable computer with data reduction software.

o Provision for thermal conditioning of the masses.

o Calibrated instruments for measuring the air density parameters.

o Automation to reduce work load.

- A pair of calibrated kilogram mass standards.

In the work reported here we have successfully provided for all of the above except for the one-kilogram mass standards. In addition we provided more automation than was anticipated in 1983 when the earlier round-robin was completed. Beyond these initial goals we also included more laboratories at greater distances to test the equipment fragility and to periodically check the correctness of the instrument calibrations. 
The laboratories included in this round-robin in sequence are:

1) May 86 - The National Bureau of Standards-Gaithersburg, Maryland.

2) June 86 - State Laboratory-Sacramento, California.

3) July 86 - State Laboratory-Honolulu, Hawaii.

4) August 86 - 3M Laboratory-St. Paul, Minnesota.*

5) September 86 - State Laboratory-Reno, Nevada.

6) October 86 - State Laboratory-Salt Lake City, Utah.

7) November 86 - State Laboratory-Denver, Colorado.

8) December 86 - Sandia Laboratory-Albuquerque, New Mexico.*

9) May 87 - State Laboratory-Albany, New York.

10) June 87 - Mound Laboratory-Miamisburg, Ohio.*

11) July 87 - The National Bureau of Standards-Gaithersburg, Maryland.

* Laboratories capable of performing instrument calibration checks.

The measurements performed during this round-robin are identical to those of the earlier work with the addition of an extra kilogram pair. The five kilograms in the package are designated A1, S2, R2, H2, and TE. Although only one kilogram was added to the package, the specified weighing technique requires the kilograms be used in pairs; as a consequence kilogram $A 1$ is lised twice. The pairings were (A1,S2), (A1, TE), and $(\mathrm{R} 2, \mathrm{H} 2)$. A brief recapitulation of the weighing scheme is given here for the convenience of the reader. Three series of measurements are performed in which each kilogram pair in the package is compared to the participating laboratory's pair of kilogram mass standards by means of substitution weighings on a single pan balance. In each series, six pairwise comparisons are made between the four kilograms involved. The resulting data are adjusted by the method of "least squares" and mass values are assigned to the kilogram pair in the package. Additionally this weighing technique yields statistical information about the weighing process and the standards. As there are three pairs of kilograms in the package, there must be three such groups of weighings performed by each participant. This method of intercomparing four like objects is referred to as a "four ones series" and is commonly used by the NIST mass calibration service.

Balance and Balance Servo

A. Balance 
Each participating laboratory has in its possession a single-pan, onekilogram capacity, substitution balance of adequate precision for routine mass calibration. All of these balances are made by the same manufacturer with some being more modern than others. However, all of them perform to the same specifications. Unfortunately, these balances are all mechanical and lack the electronic output signal necessary for automatic data acquisition. The balance weighing data are observed visually and then entered into the computer manually with the exception of the NIST balance that has been modified as described in the next section.

\section{B. Balance Servo}

At this time there is no general-purpose, single-pan balance of 1-kilogram capacity, with adequate precision for this work, and with an electronic data output. Robert D. Cutkosky, formerly of the Length and Mass Division, graciously consented to design an electronic balance servo that provided our balance with an electronic signal output. We assembled the circuit and modified the balance for use with the servo, with such success that we also installed one on the primary mass comparator here at NIST (the Voland Balance ${ }^{1}$ ). Since this is an important new addition to this project and will also be retrofitted to other balances used in the mass calibration program we will describe it in detail.

Figure 1 is the schematic diagram of the balance servo circuit. We believe that with modification of the feedback components this servo can be installed on other similar balances but we have only demonstrated this on balances with a one kilogram capacity and arm lengths of approximately $5 \mathrm{~cm}$. The balance was modified to permit the mounting of an electromagnet coil and photodetector mask to the balance beam as depicted in Fig. 2. Other modifications were performed that allowed for the mounting of permanent magnets, a photosensitive error detector using a pair of matched diodes, and electric conductors connected to the coil on the beam.

In principle the servo applies a magnetic force to the balance beam that maintains the relative position between the error detecting diodes rigidly mounted to the balance case and the photo mask attached to the free swinging beam. The force is generated by the circuit driving electrical current through the coil and the moving charges react with the fields of permanent magnets causing the desired motion of the balance beam. The circuit provides a current that is proportional to the displacement, velocity, and the time-integrated displacement of the beam whenever the photo mask is off its null position. The null position is selected by adjusting the free swinging rest point of the beam to be at the gravitational horizon. This minimizes coupling of pan swing to the beam [9] and also the offset current through the coil.

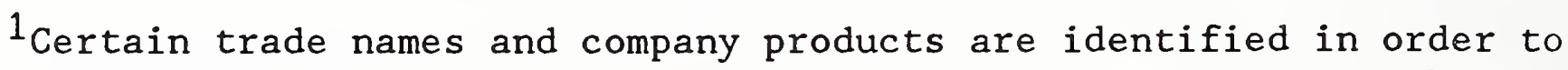
adequately specify the experimental procedure. In no case does such identification imply recommendation or endorsement by the National Institute of Standards and Technology nor does it imply that the products are necessarily the best available for the purpose. 
Figure 1. Schematic of the balance servo circuit.

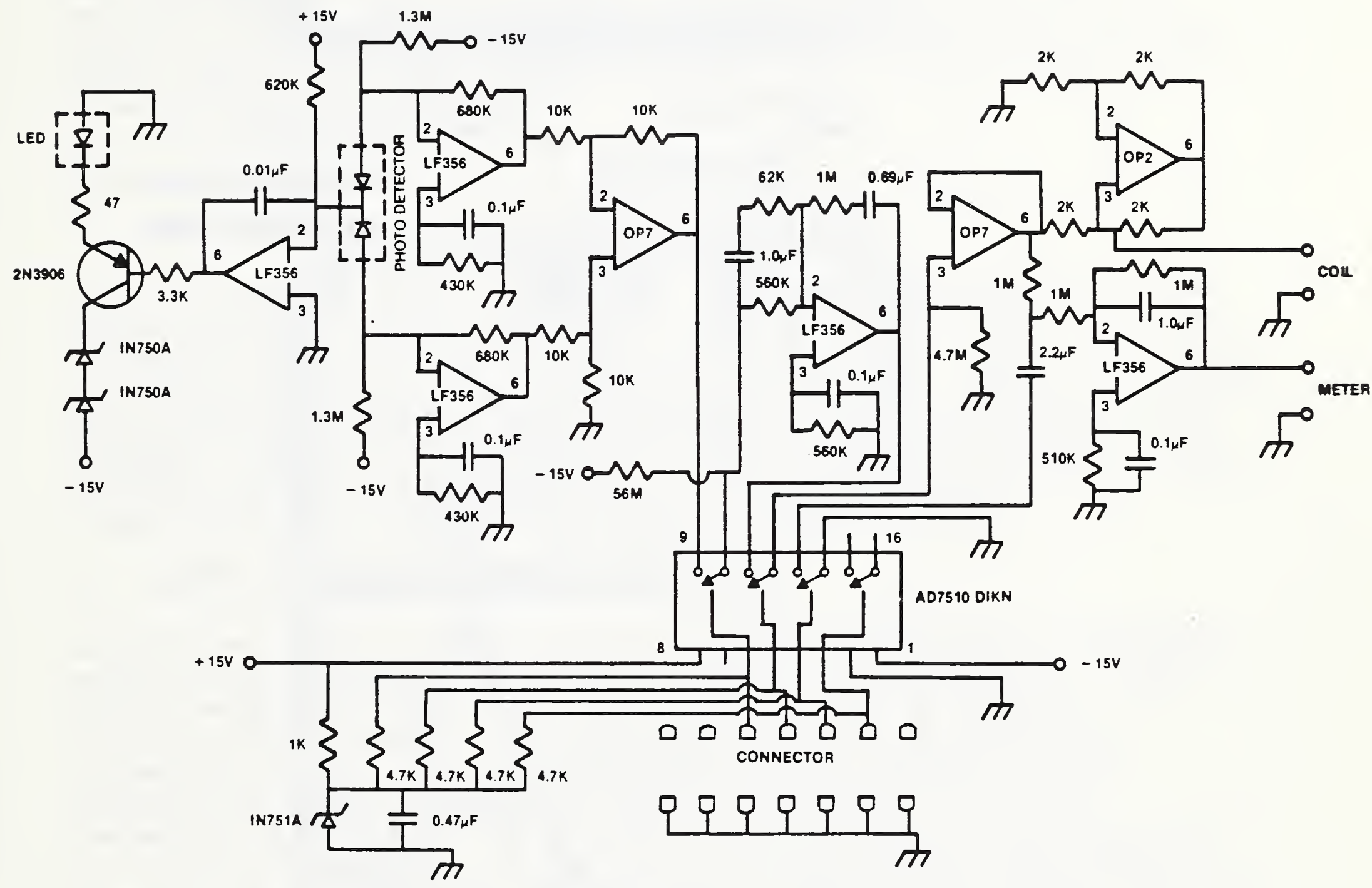


Figure 2. Configuration of balance and added servo components.

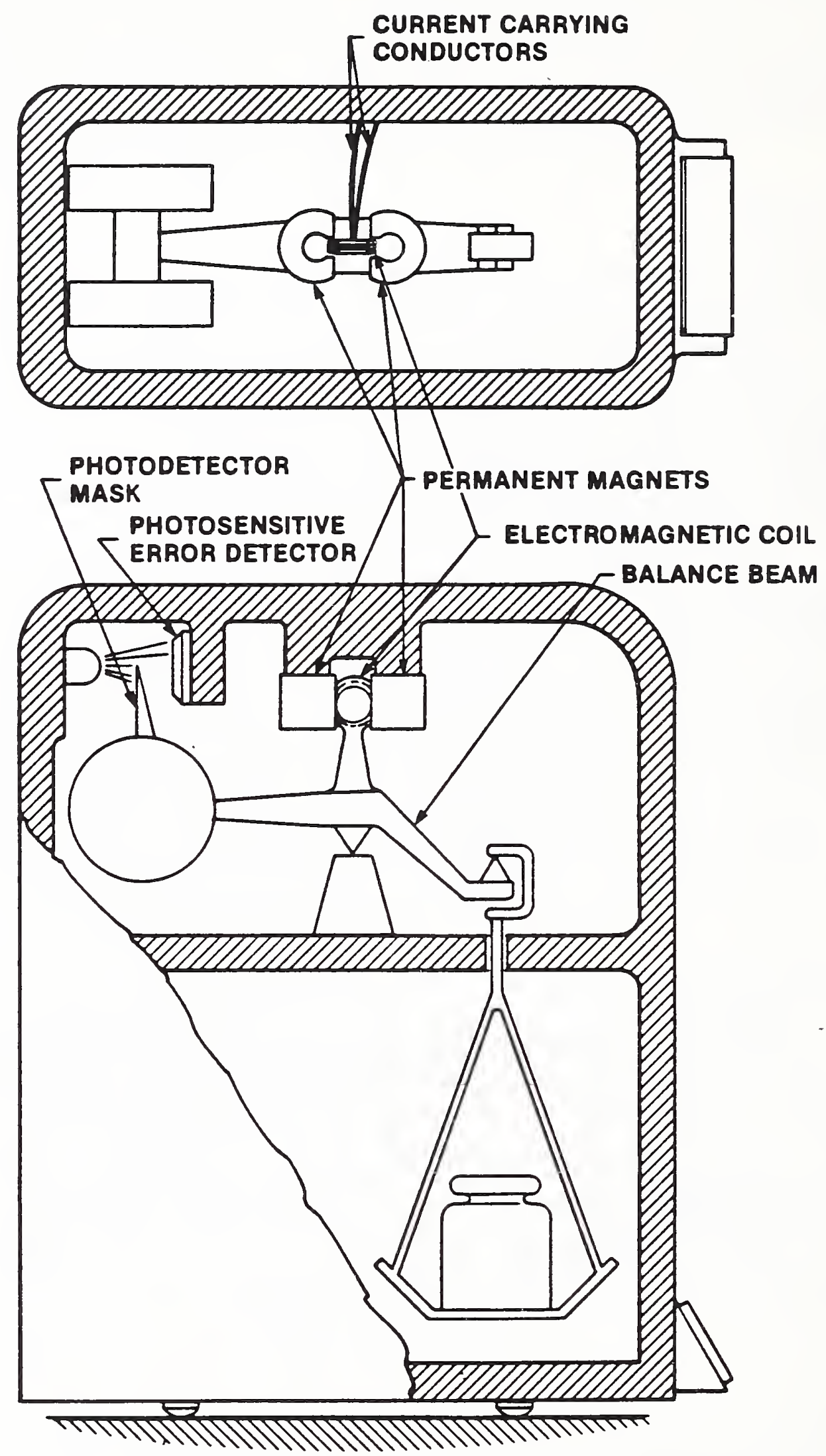


Initially the servo was tested with the balance modified to operate under constant load using a weight changing mechanism that we installed.

Operating the balance in this configuration required other extensive modifications that are, in principle, described in [10]. The results indicate a significant improvement in precision, a constant sensitivity, and a larger on-scale range. Test data indicate we could tolerate differences four times larger than the original 100 milligrams and the balance response remained linear. We found it cumbersome to use the weight changing mechanism in this work and resorted to the much faster hand loading method. In doing so the precision reverts to that of the unservoed balance but the other virtues, especially the electronic data output that makes computer data acquisition possible, remain. Table 1 summarizes the precision tests. Although the balance reproducibility was not improved when operated in the normal manner, where the knife-flat contact is broken between each load, this may not be the case for every balance. Our balance precision had deteriorated slightly from its former level, perhaps to a degree and from a source that any improvement from the servo would not be evident.

\section{Experimental Package}

\section{A. Mass Artifacts}

The mass artifacts of the package are the same as those described in our earlier work with the exception of an addition of a one-kilogram weight designated TE. In brief, all of the masses are nominally one kilogram and are made of stainless steel. The densities are in the range of 7.8 to 8.0 $\mathrm{g} / \mathrm{cm}^{3}$ except for weight $\mathrm{H} 2$ which is hollow and has a density of $2.9 \mathrm{~g} / \mathrm{cm}^{3}$. Likewise, all of the weights are of one piece construction except for S2 which is comprised of three concentric rings and a supporting base. Table 2 summarizes the pertinent characteristics for each weight.

\section{B. Thermally Controlled Soaking Plate.}

Based on our study of surface-dependent thermal effects [8] it had become evident that systematic errors arise from the lack of thermal equilibrium between weights undergoing calibration and the surrounding air in the balance weighing chamber. To remedy this situation we modified a temperature control circuit designed by Cutkosky and Davis [11] to maintain the weight-storage area outside the balance at the same temperature found inside the balance weighing chamber. A heat source that has about the same effect on the balance as the operator's body heat is also part of this solution. In essence the temperature controller has two platinum thermometer sensors, one inside the balance and one buried in a nearby aluminum soaking plate where the weights are stored. Thus the soaking plate and the weights on it are in close proximity to the temperature in the balance weighing chamber. The rise in temperature associated with the operator's presence is anticipated and simulated by an electrically resistive heat source. This source does not radiate in the visible range and is replaced by the operator during the weighing period. The soaking plate is fabricated from solid aluminum alloy $2.54 \mathrm{~cm}$ thick and is $21.6 \mathrm{~cm}$ by $45.7 \mathrm{~cm}$ in plane view. The controlled heating element 
Table 1. Comparison of balance precision using a balance in two different modes of operation.

\section{Standard Deviation}

$(\mu \mathrm{g})$

\section{Balance \\ Configuration}

- servoed beam

- constant load mode

- automatic weight changer

- unservoed beam

- knife arrestment between loads

o hand loading of weights

Test \#1 Test \#2 Test \#3

6

17

18

52

25

44 
Table 2. Physical characteristics of each weight.

\begin{tabular}{|c|c|c|c|c|c|}
\hline & \multicolumn{5}{|c|}{ Kilogram Designation } \\
\hline & A1 & $\mathbf{s} 2$ & $\mathrm{R} 2$ & $\mathrm{H} 2$ & TE \\
\hline $\begin{array}{r}\text { Mass } \\
(\mathrm{g})\end{array}$ & 1000 & 1000 & 1000 & 1000 & 1000 \\
\hline $\begin{array}{l}\text { Volume } \\
\left(\mathrm{cm}^{3}\right)\end{array}$ & 127 & 126 & 126 & 338 & 125 \\
\hline $\begin{array}{l}\text { Density } \\
\left(\mathrm{g} / \mathrm{cm}^{3}\right)\end{array}$ & 7.85 & 7.90 & 7.91 & 2.96 & 7.99 \\
\hline $\begin{array}{l}\text { Surface Area } \\
\left(\mathrm{cm}^{2}\right)\end{array}$ & 145 & 660 & 270 & 270 & 180 \\
\hline $\begin{array}{l}\text { Height Ratio } \\
\left(\mathrm{H}_{\mathrm{x}} / \mathrm{H}_{\mathrm{Al}}\right)^{1}\end{array}$ & 1.0 & 1.2 & 1.4 & 1.4 & 3.5 \\
\hline
\end{tabular}

1. $\mathrm{H}_{\mathrm{X}}\left(\mathrm{H}_{\mathrm{A} 1}, \mathrm{H}_{\mathrm{S} 2}, \mathrm{H}_{\mathrm{R} 2}, \mathrm{H}_{\mathrm{H} 2}\right.$, or $\left.\mathrm{H}_{\mathrm{TE}}\right)$ is defined as the height of each weight. 
Figure 3. Soaking plate temperature control circuit.

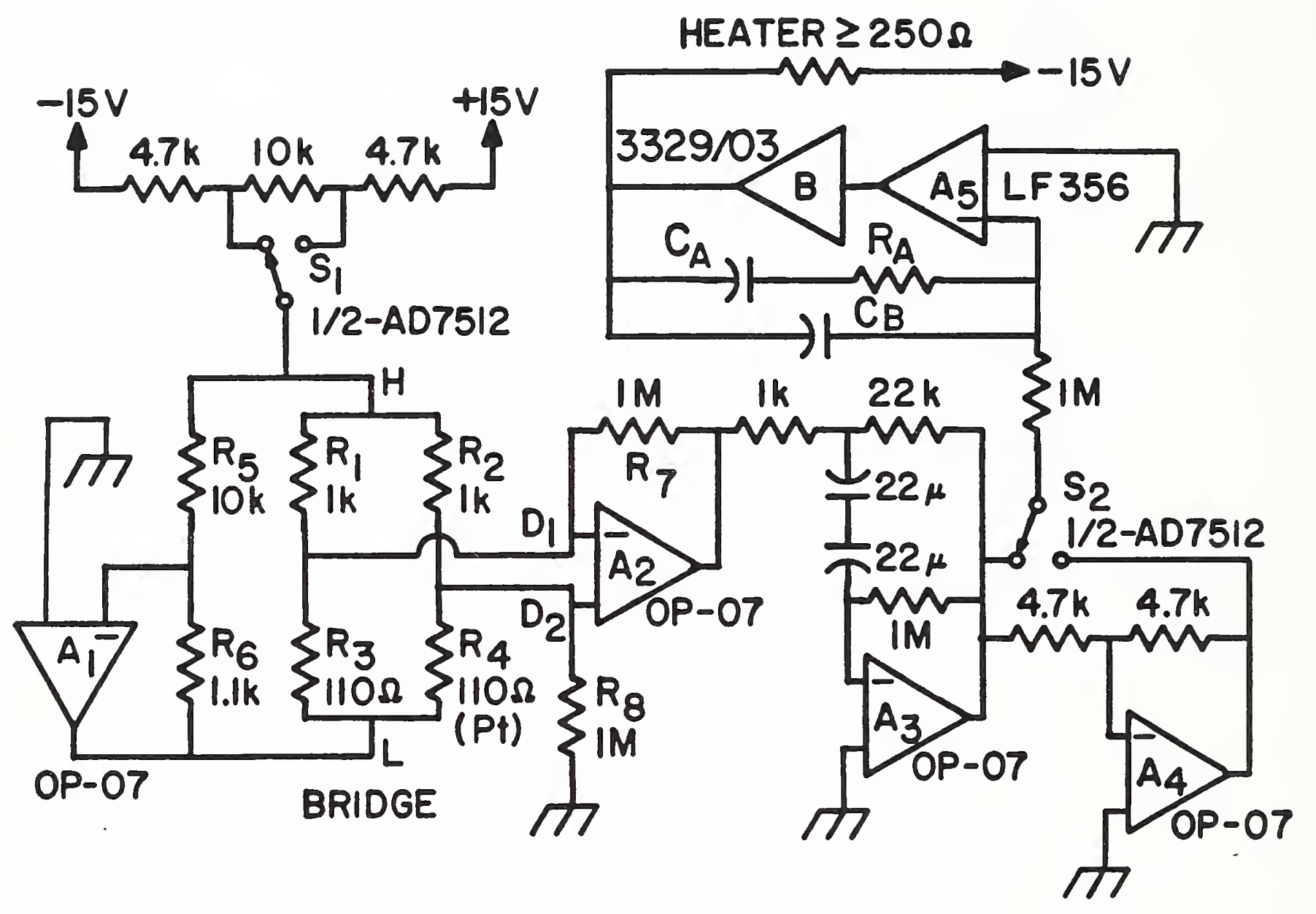


is a series hookup of 16 resisters of 16.2 ohms each. We make the following comments about the analog portion of the circuit shown in Fig.

3 .

1) A $10 \mathrm{k}$ ohm resister was added between switch $\mathrm{S} 1$ and the junction of resisters $R 1$ and $R 5$.

2) Resister $R 3$ is replaced with a 110-ohm platinum thermometer (R3 and $\mathrm{R} 4$ are both industrial quality thermometers).

3) The circuit is balanced by shunting the bridge with resisters, as necessary, to attain zero heater power when the platinum thermometers are in thermal equilibrium with each other. Shunt resisters less than $100 \mathrm{k}$ ohms are mounted on the aluminum plate to enhance the thermal stability of the circuit.

4) Capacitors $C_{A}, C_{B}$, and resister $R_{A}$ are respectively $5 \mu \mathrm{F}, 0.022$ $\mu \mathrm{F}$, and 56 megohms. These components allow the controller to regulate the temperature of a soaking plate as described above including the thermal insulation.

\section{Thermometer}

A dual probe thermistor thermometer was selected for this work because of its small probe size, speed of response, and an optional analog electrical signal output that is needed for computer data acquisition. Unfortunately the probe selection can not be computer controlled on this instrument; the selection is made manually by the operator. By experiment it was determined that the air temperature, $t$, could be calculated from the analog voltage output using the following relationship:

$$
t=84.02531 \mathrm{~V}-0.101
$$

where $V$ is the analog voltage output. For measuring air temperature one of the thermometer probes is suspended inside the balance case near the weighing pan and the other probe is buried in the aluminum soaking plate outside the balance where the weights are stored for thermal soaking before weighing.

The thermometer probe inside the balance can be monitored by the computer before and during the weighing procedure. This feature is important to assure that the thermal history prior to weighing is conducive to a successful weighing outcome. With calibration the thermometer is accurate to within $0.02{ }^{\circ} \mathrm{C}$ for either probe. Accuracy of the thermometer is achieved by calibration of both probes at several temperatures between 0 and $25^{\circ} \mathrm{C}$. This is accomplished by comparing the probes to a thermometer that is estimated to have an uncertainty in temperature of $0.003{ }^{\circ} \mathrm{C}$. Field checks on the thermometer can be obtained by comparing the probes to a mercury-in-glass thermometer inside the balance weighing chamber, or by comparing the difference between the probes themselves when they are 
thermally soaked at the same temperature; the observed difference can be compared to an established value, providing the user some assurance that the thermometer has retained its calibration.

\section{Barometer}

Of the three parameters that must be measured to compute air density -temperature, pressure, and relative humidity -- in practice, pressure is the most difficult to measure. Many laboratories do not have the means to define pressure and must rely on instruments that require calibration. Without a local source of calibration, laboratories are forced to rely on rather delicate instruments to retain their calibration in transit from distant facilities.

The needs of this measurement project are well satisfied with an accuracy of a few parts in ten thousand. We selected a capacitance pressure transducer with an electronic signal output for ease in automatic data acquisition ( 0 to 10 volts) and with a pressure range from $600 \mathrm{~mm} \mathrm{Hg}$ to $825 \mathrm{~mm} \mathrm{Hg}$. We anticipated a pressure range from $615 \mathrm{~mm} \mathrm{Hg}$ to $760 \mathrm{~mm} \mathrm{Hg}$ related to the range in elevation of the participating laboratories: from sea level to $3000 \mathrm{~m}$. The relationship between the voltage output, $\mathrm{V}$, and pressure, $P$, is as follows:

$$
P=\frac{(30 V+800)}{1.333224}+C
$$

Where $\mathrm{C}$ is a small correction determined by calibration.

To test the ruggedness of the transducer before its inclusion in the package we shipped it to Sandia laboratories where it was calibrated; as it was before and after shipment at the NIST. With the normal precautions taken in the packing and shipping of delicate instruments we had no shift in the instrument calibration during the test or the round-robin measurements.

\section{E. Relative Humidity Measurement}

The measurement of relative humidity is accomplished with a thin polymer film capacitance probe that has a fast response time. Like the other instruments described above there is an analog signal output that is useful for automatic data acquisition. The relative humidity, $\mathrm{RH}$, as a function of the voltage output is

$$
\mathrm{RH}=1000 \mathrm{~V}+\mathrm{C}
$$

where $V$ is the voltage and $C$ is a small correction determined by calibration. The range of the instrument without extrapolation is from $12 \%$ to $97 \%$ relative humidity. Over the range in relative humidity from $0 \%$ to 1008 the voltage output ranges from 0 to 0.1 volt.

The calibration of the instrument is readily performed by immersion of the 
probe into the vapor region above various saturated salt solutions [12]. The ones used here are lithium chloride (128), magnesium chloride (33\%), and potassium sulfate $(978)$. The calibration checks performed by some of the participating laboratories were not made by this method but by direct comparison to other similarly calibrated instruments. This form of calibration check holds true for the temperature and pressure instrumentation as well.

\section{F. Multiplexer}

The multimeter used to digitize the analog signals for acquisition by the computer has only a single input port and requires an external switching network for multiple inputs. Cutkosky designed a computer-controlled multiplexer. With his cooperation, we constructed a replica for this project. The multiplexer permits the computer software to control the presentation of the analog signals for acquisition by the computer. The multiplexer functioned well during the entire round-robin sequence. However, a malfunction would not necessarily be noticeable by an operator and a self-checking software routine verified that each of the four switching relays would trip and the contact resistance was acceptable before operation began in a participant laboratory.

In testing the multiplexer the operator had to become an active participant in the process, first loading into the computer and then running the appropriate program. The computer would cycle all of the relays, leave the switches in the open position and then, using the multimeter in the resistance mode, verify each switch is open. If all is well the computer instructs the operator to short each switch input with a jumper wire and then proceeds to see if the closed switch contact resistance is acceptable.

The cardinal virtues of the multiplexer are summarized below:

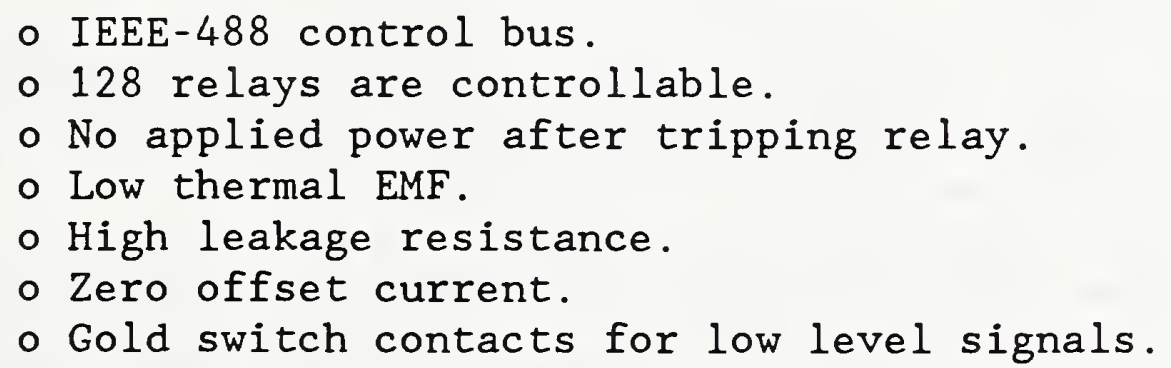

\section{G. Multimeter}

The signal outputs from the instrumentation discussed thus far are DC voltages that range from a few millivolts to no more than 10 volts. To measure these voltages and to convert them into digital information useful to the computer we selected a programmable multimeter with an IEEE-488 interface. Thus we can control the meter setup, data collection, and transfer to the computer by software commands from the computer. As we have already discussed, software control of the multiplexer determines what signal is presented to the multimeter. 
There are many features provided in the meter that we did not make use of however, the cardinal features we took advantage of are listed below:

- Five and one-half digit resolution

- Auto ranging

- Remote programing

- IEEE-488 interface

- External trigger

- High input impedance

\section{H. Computer}

The Hewlett-Packard 85 personal computer was chosen for this project for several reasons. Below is a list of properties that we felt were desirable:

- Self-contained

- Rugged

- Highly portable

- Magnetic tape cartridge mass storage

- User-friendly interfacing

- Small size

The HP-85 computer contains in one frame a 5-inch cathode ray tube display, keyboard, tape cassette, and a 32-column printer. To increase the computer's capability we added four read only memory units (ROM's), a $16 \mathrm{k}$ memory expansion module, an IEEE interface unit and an external printer. The added ROM's are:

- External input-output

- Matrix arithmetic enhancement

- Printer/Plotter enhancement

- Advanced programming

With these enhancements the computer is able to control the measurement, permit easy editing of data files, reduce the data, analyze the results, and output the desired information to an 80-column printer.

An essential part of the computer is the traveling case obtained from the manufacturer. We believe this case and the package shipping container make it possible to repeatedly ship the computer and the other equipment without damage. The shipping case is made of molded plastic and supports the computer on antishock mountings while in transit. The larger external shipping container is designed to withstand the abuse received from 100 air freight shipments and meets the Air Transportation Association Specifications 300 Category 1. Internally the computer and the other instruments are each surrounded by Dow \#220 polyethylene foam sheets that provides excellent shock protection. The outside shape of the shipping container is cubic with a distance of approximately 1 meter separating the cube faces. 


\section{Computer Software}

The three programs used in this package have been recorded onto two magnetic tape cartridges as shown in table 3. The first cartridge contains two programs which are used to test the integrity of the data acquisition system (i.e., the multiplexer, multimeter, thermometer, barometer, and relative humidity indicator). The second tape cartridge stores one main program, its subprograms, and data files which are used to record observations, analyze data, and print the results of a complete set of weighings. A sample printout of these results can be found in table 1 of appendix III. In addition, appendices I and II will describe the content and function of each tape cartridge while providing the reader with a printout of the programs found in table 3 .

\section{$\underline{\text { Results }}$}

The participants were given written instructions regarding the proper assembly, test and operation of the equipment. Certain aspects of the measurement preparation such as weight soaking time, balance warmup, and adjustment of the fixed heat source were dependent on the operator following the instructions carefully. Three laboratories (Sandia, Mound, and $3 \mathrm{M}$ ) were asked to check the calibration of the thermistor thermometer, barometer and humidity indicator and inform us if they found any significant change. Nothing irregular was detected. However, we caused a large shift in the barometer calibration after completion of the measurements while performing a recalibration at the NIST. Weight $\mathrm{H} 2$ has a very large buoyancy correction and the calculated mass is sensitive to barometer error. Our data make us confident the shift occurred after use at the Mound laboratory and not beforehand. Recalibration of the other instruments was straightforward and no significant differences were found.

On return of the package to the NIST we repeated the measurements again. The data clearly indicate that weight $\mathrm{H} 2$ lost $1 / 2 \mathrm{mg}$ of mass after calibration at Mound Laboratories and before final calibration at the NIST. This loss correlates with an obvious deep scratch on the weight surface. Although we show the data for completeness we do not use it in the analysis. Other discrepancies in the data occurred as well. Sandia Laboratories was unable to weigh kilogram TE because of its height and a previous modification of their balance pan. There are two sets of Hawaiian data, the second set is a recomputation of the first set after an NIST recalibration of their kilogram standards. Colorado violated a procedural rule that limits the difference between the standard and the unknown weight to no more than $1 / 4$ the mass of the sensitivity weight. The violation occurred on the A1-S2 weight pair and we omit the data. For completeness we present the data of our first round-robin (RR\#1) along with the second one (RR\#2) here. Tables 4, 5, and 6 present the first and second round-robin data in tabular form. Clearly, we have eliminated the difficulty the state laboratories had with the buoyancy correction for weight $\mathrm{H} 2$ during round-robin \#1. We have improved the standard deviations for each weight that was included earlier and note that weight TE (not included in $R R \# 1$ ) appears to behave as the others. The t-test was failed 
Table 3. Catalog of programs stored on the preliminary and primary tape cartridges.

\begin{tabular}{lrrrr} 
Preliminary tape cartridge: \\
NAME & TYPE & BYTES & RECS & FILE \\
TEST & PROG & 256 & 15 & 1 \\
HIST & PROG & 256 & 7 & 2 \\
\multicolumn{5}{c}{} \\
& & & \\
Primary tape cartridge: & & \\
& & & & \\
NAME & TYPE & BYTES & RECS & FILE \\
AUtost & PROG & 256 & 5 & 1 \\
INPUT & PROG & 256 & 12 & 2 \\
MEASUR & PROG & 256 & 13 & 3 \\
EDITD & PROG & 256 & 23 & 4 \\
ANALY & PROG & 256 & 26 & 5 \\
SUBRHO & PROG & 256 & 4 & 6 \\
PRINTM & PROG & 256 & 4 & 7 \\
A MAIN & DATA & 80 & 12 & 8 \\
B MAIN & DATA & 80 & 12 & 9 \\
C MAIN & DATA & 80 & 12 & 10 \\
TRANSD & PROG & 256 & 9 & 11
\end{tabular}


in every instance for the New York data during the second round-robin and indicates the state kilograms need recalibration. This information is a useful byproduct of the round-robin.

Hawaii was the second participating laboratory to receive the package from NIST. We noted that based on our experience we thought the Hawaiian kilograms appeared to need recalibration. This was accomplished by us and explains the recalculation of the Hawailan data. We found the mass of both kilograms in the uncleaned condition, as they were received from Hawaii, to be virtually unchanged but in preparing for an after cleaning calibration we routinely measured their densities. Recalculation of the data with the measured densities brings the Hawaiian measurements in agreement with the others. Recalibration of the Hawaii kilograms after cleaning showed a mass loss of about 150 micrograms per kilogram (i.e., the dirt compensated for the wear). More discussion on the matter of artifact density occurs later in the text.

In performing the measurements reported here, each participating laboratory used their pair of calibrated standard kilogram to make mass assignments to the artifacts in the round-robin package. The assigned mass values of these standard kilogram pairs can be offset from the others by 100 micrograms or more based on their calibration uncertainty statements. These offsets then manifest themselves in the subsequent artifact calibration. We have removed these offsets, for the purpose of comparison, before performing additional analysis by normalizing the A1 mass values and then adjusting the other artifact data accordingly. Kilogram Al was chosen to normalize the data because its characteristics are similar to the participants' standard kilograms. The adjustment factor for each participant was obtained by subtracting their averaged A1 values from the grand average of all the A1 values. This factor was then added algebraically to the assigned masses of the remaining kilograms. We refer to these data as the adjusted data and show it in table 7 .

For RR\#2 the adjustment factor never exceeds 100 micrograms and is a negative 100,60 , and 56 micrograms respectively for the states of Nevada, Utah, and Colorado - - all high-altitude locations. We shall speculate on the significance of this finding later in the text. Comparing the standard deviations of these tables to those given in tables 4, 5, and 6 we see an across-the-board improvement in the data for both round-robins.

We solicited the assistance of the Statistical Engineering Division to perform additional statistical tests on the data. In particular we wanted to look for correlation between the artifact masses and the air density parameters of barometric pressure, air temperature, and relative humidity. In addition we wanted to look for correlation with mass and the difference between the initial temperature and the final temperature found inside the balance during the weighing period. We refer to this difference as delta $T$. Kilogram TE was specifically designed to be sensitive to this temperature difference [8]. These data are given in table 8 and the analysis in table 9 . We quote the summary here: 
Table 4. Assigned mass values for weight pair A1-S2, given for both roundrobins.

Round-robin \#1:

\begin{tabular}{|c|c|c|c|}
\hline & & Desi & ation \\
\hline & & A1 & S2 \\
\hline Lab & Date & 1000 & 999 \\
\hline$N I S T^{3}$ & $4 / 82-4 / 83$ & $\begin{array}{c}(\mathrm{g}) \\
.009132\end{array}$ & $\begin{array}{c}(\mathrm{g}) \\
.988553\end{array}$ \\
\hline New York & $5 / 82$ & .009295 & .988625 \\
\hline California & $6 / 82$ & .009301 & .988789 \\
\hline Nevada & $8 / 82$ & .009070 & .988476 \\
\hline Sandia & $11 / 82$ & .009102 & .988739 \\
\hline Colorado & $2 / 83$ & .009068 & .988602 \\
\hline Utah & $3 / 83$ & .009239 & .988689 \\
\hline & $\overline{\mathrm{X}} \quad=$ & .009172 & .988782 \\
\hline & S.D. $=$ & 0.000103 & 0.000377 \\
\hline
\end{tabular}

Round-robin \#2:

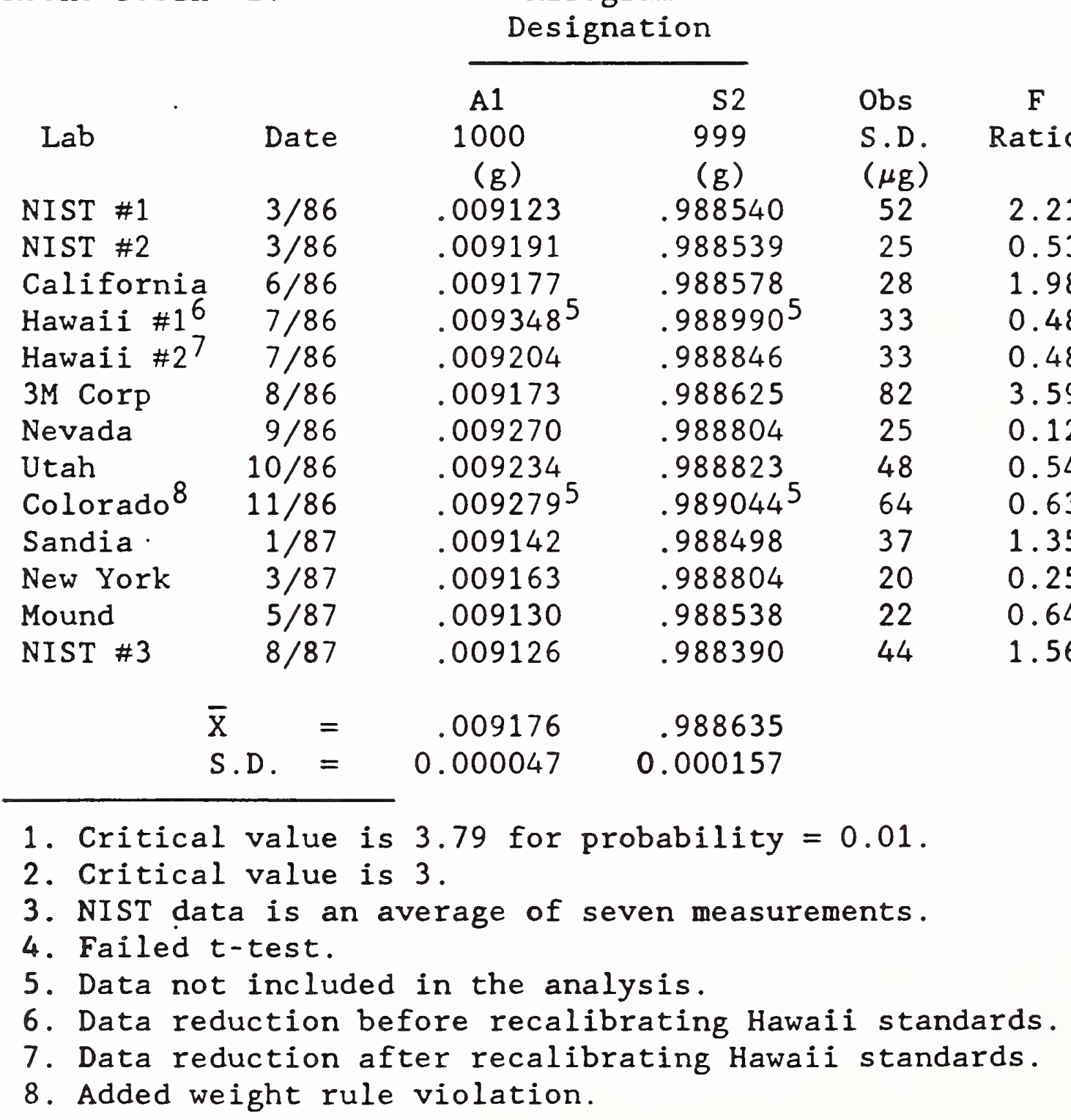

Check

Std

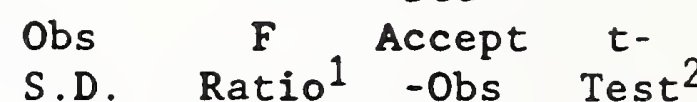

$(\mu g)$

$(\mu \mathrm{g})$

-
21
47
79
61
54
34

0.26

$-86$

$3.04^{4}$

$0.61-4$

0.09

$\begin{array}{lll}1.75 & -71 & -1.68\end{array}$

$\begin{array}{lll}2.74 & 14 & -2.63\end{array}$

$\begin{array}{lll}1.72 & 4 & -0.89\end{array}$

$\begin{array}{lll}0.32 & -38 & 0.90\end{array}$

\section{Accept}

Diff

-Obs $t$ -

Diff Test

$(\mu g)$

$5 \quad-0.21$

$\begin{array}{ll}-66 & 2.67\end{array}$

$37-2.61$

$34-1.00$

$4-0.12$

$37-1.21$

$\begin{array}{ll}-6 & 0.12\end{array}$

$\begin{array}{ll}73 & -1.59\end{array}$

$82 \cdot-1.43$

$23-1.01$

$\begin{array}{ll}106 & -3.74^{4}\end{array}$

$\begin{array}{ll}-4 & 0.20\end{array}$

$\begin{array}{ll}-66 & 2.68\end{array}$ 
Table 5. Assigned mass values for weight pair R2-H2, given for both roundrobins.

Round-robin \#1:

\begin{tabular}{|c|c|c|c|c|c|c|c|}
\hline \multirow[t]{2}{*}{ 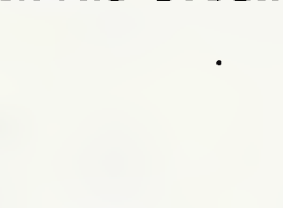 } & & \multicolumn{2}{|c|}{$\begin{array}{l}\text { Kilogram } \\
\text { Designation }\end{array}$} & \multirow{3}{*}{$\begin{array}{l}\text { Obs } \\
\text { S.D. } \\
(\mu g)\end{array}$} & \multicolumn{2}{|r|}{$\begin{array}{l}\text { Check } \\
\text { Std }\end{array}$} & \multirow[b]{2}{*}{$t-$} \\
\hline & & R2 & H2 & & $F$ & Accept & \\
\hline Lab & Date & $\begin{array}{l}999 \\
(g)\end{array}$ & $\begin{array}{r}1000 \\
(\mathrm{~g})\end{array}$ & & Ratio & $\begin{array}{l}- \text { Obs } \\
(\mu g)\end{array}$ & Test \\
\hline NIST & $4 / 82-4 / 83$ & .994503 & .003880 & - & - & - & - \\
\hline New York & $5 / 82$ & .994655 & .005980 & 35 & 0.35 & -62 & 1.45 \\
\hline California & $6 / 82$ & .994742 & .004544 & 42 & 0.49 & -31 & 0.73 \\
\hline Nevada & $8 / 82$ & .994471 & .004643 & 65 & 1.16 & 84 & -1.97 \\
\hline Sandia & $11 / 82$ & .994436 & .004143 & 60 & 2.85 & 2 & -1.59 \\
\hline Colorado & $2 / 83$ & .994580 & .004642 & 65 & 0.82 & -38 & 0.08 \\
\hline Utah & $3 / 83$ & .994788 & .003816 & 54 & 0.16 & 5 & -0.12 \\
\hline
\end{tabular}

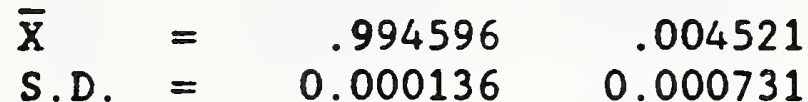

Round-robin \#2:

\begin{tabular}{|c|c|c|c|c|c|c|c|}
\hline & & $\begin{array}{l}\text { Kilo } \\
\text { Desig }\end{array}$ & $\begin{array}{l}\text { ram } \\
\text { ation }\end{array}$ & & & Accept & \\
\hline & & R2 & H2 & Obs & $F$ & -Obs & $t-$ \\
\hline Lab & Date & $\begin{array}{l}999 \\
(\mathrm{~g})\end{array}$ & $\begin{array}{r}1000 \\
(\mathrm{~g})\end{array}$ & $\begin{array}{l}\text { S.D. } \\
(\mu g)\end{array}$ & Ratio & $\begin{array}{l}\text { Diff } \\
(\mu g)\end{array}$ & Test \\
\hline NIST \#1 & $3 / 86$ & .994417 & .003937 & 33 & 0.88 & -5 & 0.19 \\
\hline NIST \#2 & $3 / 86$ & .994429 & .003944 & 29 & 0.67 & -68 & 2.77 \\
\hline California & $6 / 86$ & .994453 & .003973 & 24 & 1.43 & 16 & -1.16 \\
\hline Hawaii \#1 & $7 / 86$ & $.994661^{1}$ & $.004237^{1}$ & 93 & 3.73 & 33 & -0.98 \\
\hline Hawaii \#2 & $7 / 86$ & .994517 & .004093 & 93 & 3.73 & 3 & -0.10 \\
\hline $3 M$ Corp & $8 / 86$ & .994537 & .004058 & 45 & 1.06 & -30 & 0.99 \\
\hline Nevada & $9 / 86$ & .994677 & .004137 & 78 & 1.15 & 14 & -0.28 \\
\hline Utah & $10 / 86$ & .994708 & .004094 & 46 & 0.50 & 99 & -2.16 \\
\hline Colorado & $11 / 86$ & .994804 & .004384 & 71 & 0.76 & 117 & -2.04 \\
\hline Sandia & $1 / 87$ & .994476 & .004037 & 56 & 3.08 & -44 & 1.95 \\
\hline New York & $3 / 87$ & .994566 & .004109 & 34 & 0.70 & 102 & $-3.59^{2}$ \\
\hline Mound & $5 / 87$ & .994494 & .003949 & 49 & 3.32 & 21 & -1.12 \\
\hline NIST \#3 & $8 / 87$ & .994368 & $.003482^{1,3}$ & 49 & 1.96 & -57 & 2.30 \\
\hline NIST \#4 & $8 / 87$ & $.994390^{1}$ & $.003504^{1,3}$ & 62 & 3.18 & -126 & $5.07^{2}$ \\
\hline & $=$ & .994537 & .004065 & & & & \\
\hline & D. $=$ & 0.000131 & 0.000128 & & & & \\
\hline
\end{tabular}

1. Data not used in the analysis.

2. Failed t-test.

3. Damaged weight (see text). 
Table 6. Assigned mass values for weight pair A1-TE. The pair A1-TE was not used in round-robin \#1.

Round-robin \#2:

Kilogram

Designation

\begin{tabular}{|c|c|c|c|c|c|c|c|}
\hline & & & & & & & \\
\hline & & A1 & TE & Obs & $F$ & -Obs & $t-$ \\
\hline Lab & Date & $\begin{array}{r}1000 \\
(g)\end{array}$ & $\begin{array}{r}1000 \\
(\mathrm{~g})\end{array}$ & $\begin{array}{l}\text { S.D. } \\
(\mu g)\end{array}$ & Ratio & $\begin{array}{l}\text { Diff } \\
(\mu g)\end{array}$ & Test \\
\hline NIST \#1 & $3 / 86$ & .009195 & .002105 & 59 & 2.81 & -34 & 1.36 \\
\hline NIST \#2 & $3 / 86$ & .009096 & .002082 & 53 & 2.32 & -38 & 1.54 \\
\hline California & $6 / 86$ & .009226 & .002277 & 46 & 5.28 & -33 & 2.37 \\
\hline Hawaii \#1 & $7 / 86$ & $.009261^{1}$ & $.002520^{1}$ & 55 & 1.33 & 101 & -2.98 \\
\hline Hawaii \#2 & $7 / 86$ & .009117 & .002376 & 55 & 1.33 & 71 & -2.10 \\
\hline $3 M$ Corp & $8 / 86$ & .009211 & .002373 & 59 & 1.83 & -5 & 0.18 \\
\hline Nevada & $9 / 86$ & .009285 & .002457 & 70 & 0.92 & -34 & 0.65 \\
\hline Utah & $10 / 86$ & .009242 & .002389 & 74 & 1.29 & -32 & 0.69 \\
\hline Colorado & $11 / 86$ & .009188 & .002519 & 23 & 0.84 & 69 & -1.20 \\
\hline Sandia ${ }^{1}$ & $1 / 87$ & - & - & - & - & - & - \\
\hline New York & $3 / 87$ & .009187 & .002273 & 34 & 0.71 & 86 & $3.05^{2}$ \\
\hline Mound & $5 / 87$ & .009127 & .002301 & 14 & 0.28 & 20 & -1.05 \\
\hline NIST \#3 & $8 / 87$ & .009114 & .002059 & 57 & 2.65 & -55 & 2.23 \\
\hline & & .009181 & .002292 & & & & \\
\hline & D. $=$ & 0.000060 & 0.000154 & & & & \\
\hline
\end{tabular}

1. Modified balance pan cannot accommodate extraordinary height of weight TE.

2. Failed t-test. 
Table 7. Assigned mass values of weights S2, R2, H2, and TE normalized to weight A1.

Round-robin \#1:

Kilogram Designation

\begin{tabular}{|c|c|c|c|c|}
\hline & & s2 & R2 & $\mathrm{H} 2$ \\
\hline Lab & Date & $\begin{array}{l}999 \\
(g)\end{array}$ & $\begin{array}{l}999 \\
(\mathrm{~g})\end{array}$ & $\begin{array}{r}1000 \\
(\mathrm{~g})\end{array}$ \\
\hline ST & $4 / 82-4 / 83$ & .988593 & .994543 & .003920 \\
\hline w York & $5 / 82$ & .988502 & .994532 & .005857 \\
\hline lifornia & $6 / 82$ & .988660 & .994613 & .004415 \\
\hline vada & $8 / 82$ & .988578 & .994573 & .004745 \\
\hline ndia & $11 / 82$ & .988809 & .994506 & .004213 \\
\hline lorado. & $2 / 83$ & .988706 & .994684 & .004746 \\
\hline & $3 / 83$ & .988622 & .994721 & .003749 \\
\hline & & .988639 & .994596 & .004521 \\
\hline & S.D. = & 0.000099 & 0.000081 & 0.000701 \\
\hline
\end{tabular}

Round-robin \#2:

Kilogram Designation

\begin{tabular}{|c|c|c|c|c|c|c|}
\hline & & s2 & R2 & $\mathrm{H} 2$ & TE & $\begin{array}{l}\text { Adjust } \\
\text { Factor }\end{array}$ \\
\hline $\mathrm{Lab}$ & Date & $\begin{array}{l}999 \\
(\mathrm{~g})\end{array}$ & $\begin{array}{l}999 \\
(g)\end{array}$ & $\begin{array}{r}1000 \\
(\mathrm{~g})\end{array}$ & $\begin{array}{r}1000 \\
(\mathrm{~g})\end{array}$ & $\begin{array}{c}\overline{\mathrm{A}} 1-\mathrm{A} 1 \\
(\mu \mathrm{g})\end{array}$ \\
\hline NIST \#1 & $3 / 86$ & .988559 & .994436 & .003956 & .002124 & 19 \\
\hline NIST \#2 & $3 / 86$ & .988573 & .994462 & .003978 & .002116 & 34 \\
\hline California & $6 / 86$ & .988554 & .994429 & .003949 & .002253 & -24 \\
\hline Hawaii & $7 / 86$ & .988864 & .994535 & .004111 & .002394 & 18 \\
\hline $3 M$ Corp & $8 / 86$ & .988611 & .994523 & .004044 & .002359 & -14 \\
\hline Nevada & $9 / 86$ & .988704 & .994577 & .004037 & .002357 & -100 \\
\hline Utah & $10 / 86$ & .988763 & .994648 & .004034 & .002329 & -60 \\
\hline Colorado & $11 / 86$ & 1 & .994748 & .004328 & .002463 & -56 \\
\hline Sandia. & $1 / 87$ & .988534 & .994512 & .004073 & $\overline{2}$ & 36 \\
\hline New York & $3 / 87$ & .988807 & .994569 & .004112 & .002276 & 3 \\
\hline Mound & $5 / 87$ & .988588 & .994544 & .003999 & .002351 & 50 \\
\hline NIST \#3 & $8 / 87$ & .988448 & .994426 & & .002117 & 58 \\
\hline & & .988637 & .994534 & .004056 & .002285 & \\
\hline & D. $=$ & 0.000129 & 0.000095 & 0.000106 & 0.000120 & \\
\hline
\end{tabular}

1. Added weight violation.

2. Balance modification.

3. Damaged weight. 
Table 8. Correlation test data.

\begin{tabular}{|c|c|c|c|c|c|}
\hline Kilogram & $\begin{array}{c}\text { Adj. Mass } \\
\text { (g) }\end{array}$ & $\begin{array}{c}\text { Temperature } \\
\left({ }^{\circ} \mathrm{C}\right)\end{array}$ & $\begin{array}{l}\text { Pressure } \\
(\mathrm{mm} \mathrm{Hg})\end{array}$ & $\begin{array}{c}\text { Humidity } \\
(\&)\end{array}$ & $\begin{array}{r}\Delta \text { Temp } \\
\left(\begin{array}{c}0 \\
0\end{array}\right)\end{array}$ \\
\hline \multirow[t]{11}{*}{ S2 } & 999.988559 & 24.08 & 761.25 & 32.7 & -0.01 \\
\hline & 999.988573 & 24.24 & 752.44 & 27.8 & 0.02 \\
\hline & 999.988554 & 23.30 & 759.58 & 38.4 & 0.00 \\
\hline & 999.988864 & 23.36 & 762.30 & 23.8 & 0.01 \\
\hline & 999.988611 & 22.67 & 737.26 & 33.5 & -0.01 \\
\hline & 999.988704 & 24.40 & 646.41 & 18.8 & 0.09 \\
\hline & 999.988763 & 23.74 & 656.26 & 26.8 & 0.10 \\
\hline & 999.988534 & 20.87 & 627.17 & 38.1 & -0.02 \\
\hline & 999.988807 & 21.20 & 762.44 & 40.6 & 0.18 \\
\hline & 999.988588 & 22.96 & 743.61 & 33.4 & 0.04 \\
\hline & 999.988448 & 24.20 & 748.63 & 53.5 & 0.00 \\
\hline \multirow[t]{12}{*}{ R2 } & 999.994436 & 24.27 & 756.77 & 34.0 & 0.02 \\
\hline & 999.994462 & 24.05 & 759.64 & 27.5 & 0.03 \\
\hline & 999.994429 & 23.27 & 759.13 & 38.4 & 0.00 \\
\hline & 999.994535 & 23.39 & 763.10 & 24.0 & -0.06 \\
\hline & 999.994523 & 22.59 & 743.66 & 32.8 & 0.00 \\
\hline & 999.994577 & 24.14 & 645.08 & 17.0 & 0.15 \\
\hline & 999.994648 & 23.12 & 655.87 & 32.7 & 0.07 \\
\hline & 999.994748 & 22.37 & 619.10 & 32.3 & -0.02 \\
\hline & 999.994512 & 20.84 & 626.63 & 37.3 & -0.10 \\
\hline & 999.994569 & 22.79 & 751.60 & 33.6 & 0.01 \\
\hline & 999.994544 & 22.97 & 743.44 & 33.5 & 0.02 \\
\hline & 999.994426 & 24.24 & 754.14 & 49.2 & 0.01 \\
\hline \multirow[t]{11}{*}{$\mathrm{H} 2$} & 1000.003956 & 24.27 & 756.77 & 34.0 & 0.02 \\
\hline & 1000.003978 & 24.05 & 759.64 & 27.5 & 0.03 \\
\hline & 1000.003949 & 23.27 & 759.13 & 38.4 & 0.00 \\
\hline & 1000.004111 & 23.39 & 763.10 & 24.0 & -0.06 \\
\hline & 1000.004044 & 22.59 & 743.66 & 32.8 & 0.00 \\
\hline & 1000.004037 & 24.14 & 645.08 & 17.0 & 0.15 \\
\hline & 1000.004034 & 23.12 & 655.87 & 32.7 & 0.07 \\
\hline & 1000.004328 & 22.37 & 619.10 & 32.3 & -0.02 \\
\hline & 1000.004073 & 20.84 & 626.63 & 37.3 & -0.10 \\
\hline & 1000.004112 & 22.79 & 751.60 & 33.6 & 0.01 \\
\hline & 1000.003999 & 22.97 & 743.44 & 33.5 & 0.02 \\
\hline \multirow[t]{11}{*}{$\mathrm{TE}$} & 1000.002124 & 24.29 & 741.27 & 41.4 & -0.01 \\
\hline & 1000.002116 & 24.21 & 753.34 & 30.7 & 0.02 \\
\hline & 1000.002253 & 23.25 & 759.50 & 35.6 & 0.06 \\
\hline & 1000.002394 & 23.52 & 762.45 & 23.3 & 0.13 \\
\hline & 1000.002359 & 22.61 & 745.70 & 33.2 & -0.01 \\
\hline & 1000.002357 & 25.47 & 641.38 & 16.1 & 0.15 \\
\hline & 1000.002329 & 23.58 & 657.15 & 28.1 & 0.01 \\
\hline & 1000.002463 & 21.68 & 630.45 & 30.6 & 0.13 \\
\hline & 1000.002276 & 22.96 & 744.21 & 36.6 & 0.09 \\
\hline & 1000.002351 & 23.01 & 743.24 & 33.1 & 0.03 \\
\hline & 1000.002117 & 24.34 & 755.54 & 49.7 & 0.00 \\
\hline
\end{tabular}


Table 9. Correlation of Mass with Environmental Parameters.

Kilogram Designation

S2

R2

$\mathrm{H} 2$

TE

Temperature
Pressure
Humidity
$\Delta$ Temperature

Temperature

Pressure

Humidity

$\Delta$ Temperature

Temperature

Pressure

Humidity

$\Delta$ Temperature

Temperature

Pressure

Humidity

$\Delta$ Temperature
Correlation

Coefficient

$-0.14$

$-0.03$

$-0.58$

$+0.64$

$-0.38$

$-0.70$

$-0.36$

$+0.12$

$-0.44$

$-0.54$

$-0.08$

$-0.29$

$-0.53$

$-0.53$

$-0.64$

$+0.62$
Correlation Coefficient 958 Confidence Interval

Nevada, Utah, and Colorado excluded:

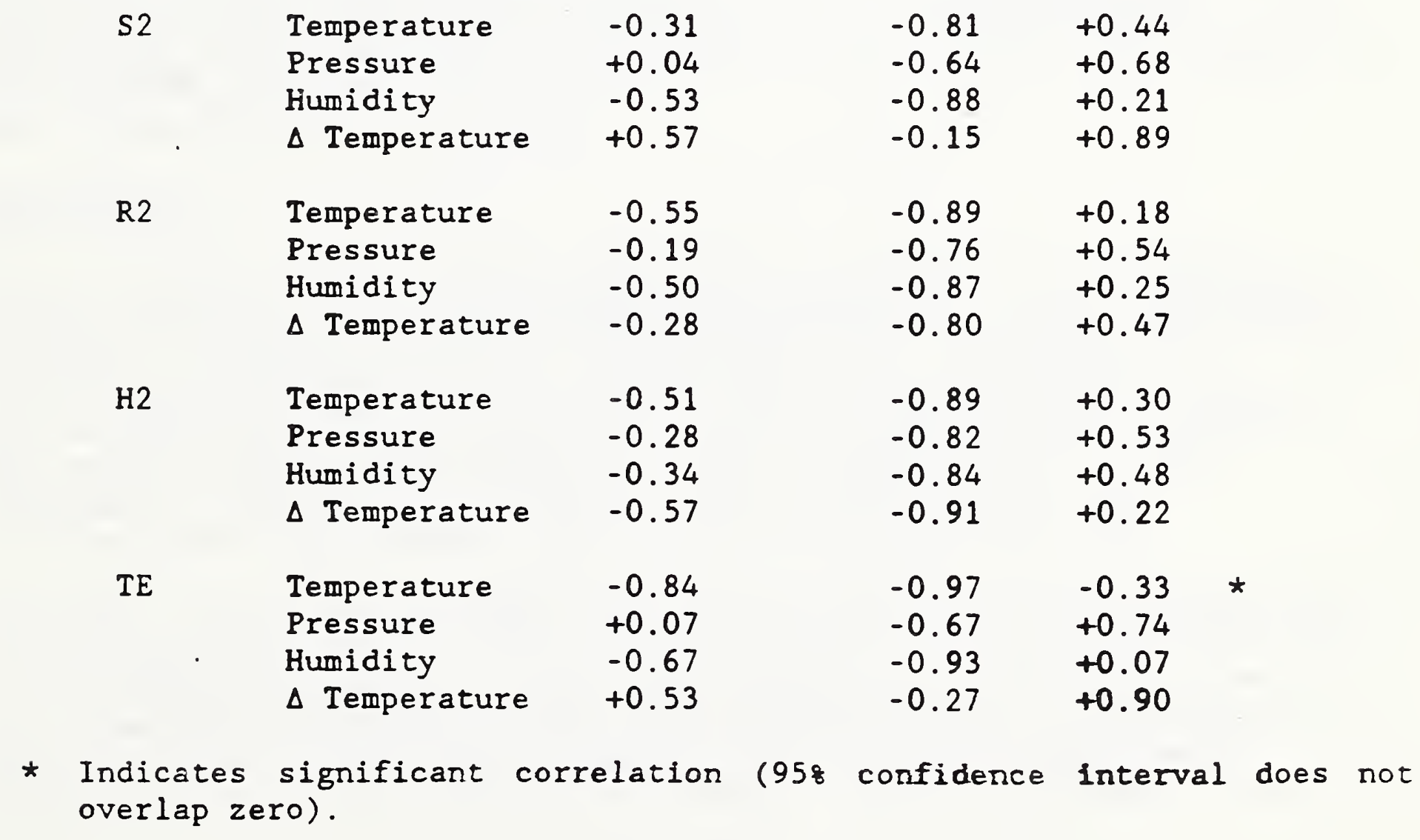


Table 10. - Measurement series temperature change. $\mathrm{T}_{\mathrm{i}}=$ initial temperature

$\mathrm{T}_{\mathrm{f}}=$ final temperature

$$
\Delta T=T_{f}-T_{i}
$$

Round-robin \#2:

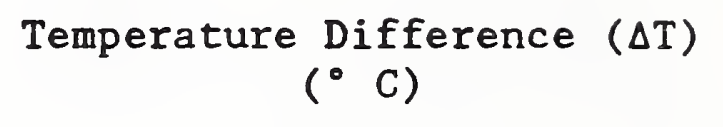

\section{Lab}

NIST \#1

NIST \#2

$\mathrm{CA}$

Hawaii

3M Corp

Nevada

Utah

Colorado

Sandia

New York

Mound

NIST \#3

NIST \#4
A1-S2 R2-H2 A1-TE

$-0.01$

0.02

0.02

0.03

0.00

0.00

0.01

$-0.06$

$-0.01$

0.00

0.15

0.09

0.10

0.07

$-0.02$

$-0.02-0.10$

0.18

0.01

0.02

0.01

0.05

$-0.01$

0.02

0.06

0.13

$-0.01$

0.15

0.01

0.13

0.04

0.09

0.03

0.00

0.00

$-$ 
"Note that on an individual basis the correlation is significant at the 0.05 level in only four cases, as indicated by a "*." However, when considering the data for the four kilograms as whole, there are strong indications that

1) mass is negatively correlated with temperature, pressure, and humidity,

2) mass is positively correlated with delta temperature."

Only kilogram R2 has significant correlation with barometric pressure and therefore we suspected the weight volume was in error. However, a new volume determination agreed with the former one to within 1 part in $10^{4}$, a null result. We expected correlation with kilogram TE due to thermal effects [8] but not the general correlation of all the kilograms with all of the parameters, particularly relative humidity. Our data yields a negative correlation where a positive correlation is known [13]. We recalled during the volume measurement on Hawaii's kilogram that the assigned volumes to state kilograms were assumed and not measured at the time of their calibration. This occurred during the 1970's and before, when volume measurements were not economical. We performed a second analysis but omitted the data from Colorado, Nevada, and Utah. This analysis is summarized in the lower part of table 9 and indicates only one significant correlation, kilogram TE with delta $\mathrm{T}$. The kilograms and the observed delta $\mathrm{T}$ are given in table 10. There remains a suggestion of a negative correlation of mass with temperature and relative humidity that we cannot explain other than possible instrumentation errors. However, the resulting mass errors are well below the noise level of these measurements or any practical routine mass measurement. Fig. 4 is a typical graphic illustration of both sets of analysis, we only show the data for kilogram R2 where earlier we had considered a volume error. In Fig. 5 we have denoted the weight pairing of kilogram Al at the time of weighing. It is gratifying to note that the mass assigned to kilogram A1 is not correlated with the unusual features of kilograms S2 and TE. Other aspects of Fig. 5 are discussed later in the text.

\section{Conclusions}

First, let us consider only the improvement we observe in our ability to weigh kilogram $\mathrm{H} 2$. The volume difference between $\mathrm{H} 2$ and the participants standards' is about two orders of magnitude larger than the other kilogram combinations. We note that in round-robin \#1 the weighing data was unacceptable while that of round-robin \#2 is as good as can be expected [6] and not significantly different from the behavior of the other kilograms. This certainly indicates that the improvements in instrumentation and thermal conditioning are working very well.

Secondly, the mass of kilogram $\mathrm{TE}$ is the only mass that has a significant correlation with delta $T$. The height of $T E$ is about three times that of a standard kilogram, similar to $A 1$, whose height is approximately equal to its diameter. Futhermore we note that the surface area of kilogram $S 2$ is about 4.5 times larger than a standard kilogram and no significant correlation with any parameter was detected. These data suggest that we 
Figure 4. Scatter plots of correlated and uncorrelated data for kilogram R2.

Correlation Plots of Mass Values Assigned to Kilogram R2 Versus Temperature, Pressure, Relative Humidity, and $\Delta T$

With Nevada, Utah, and Colorado

Kilogram R2

(999 g)
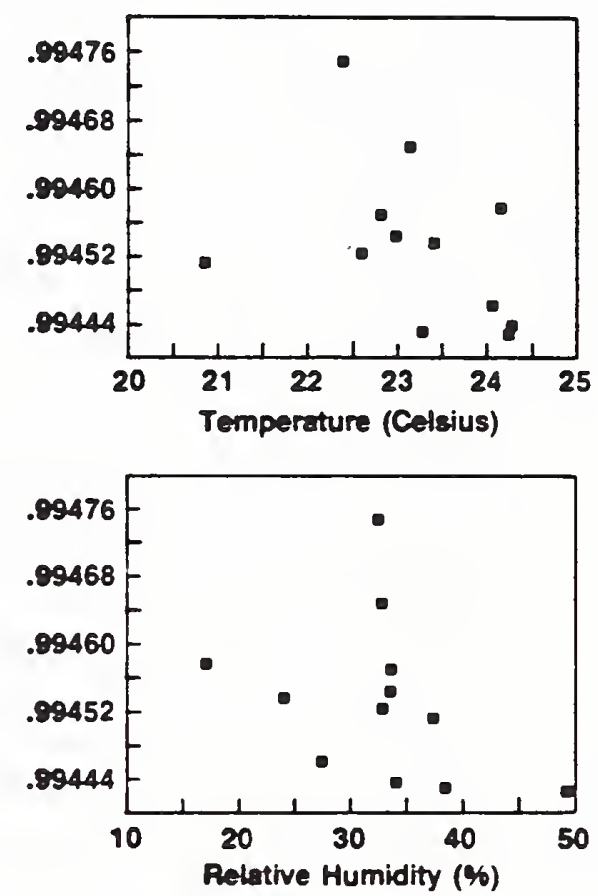

Without Nevada, Utah, and Colorado

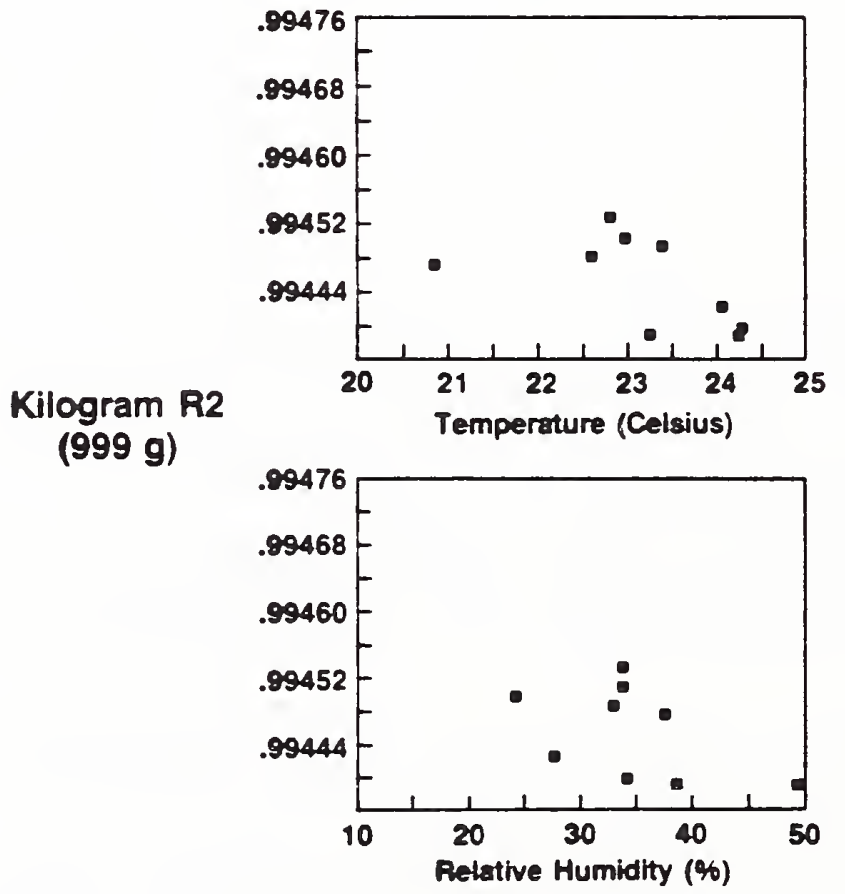

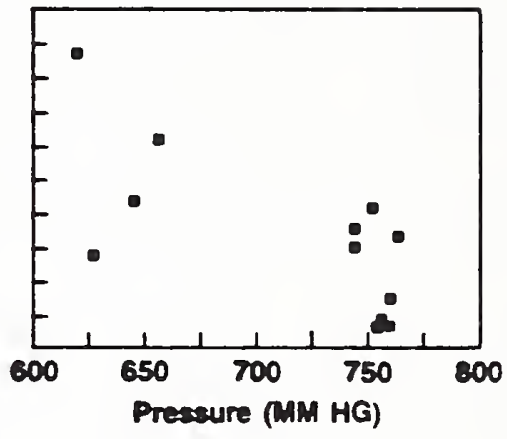

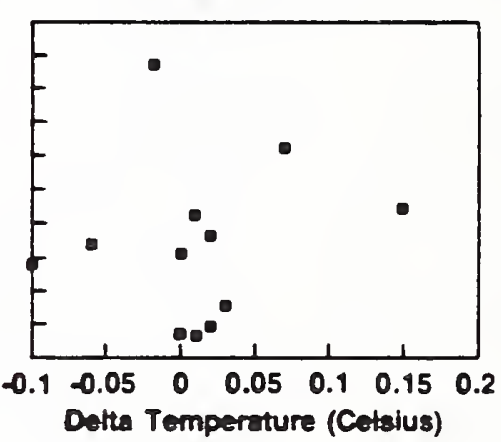

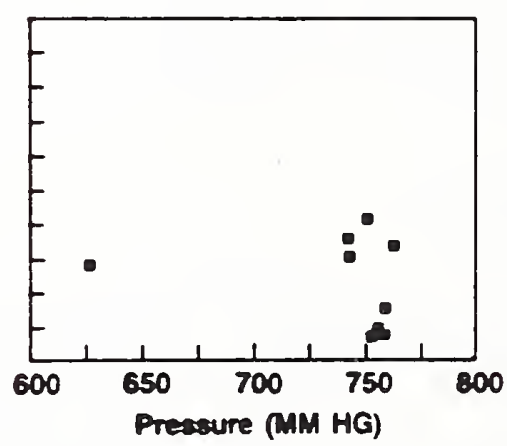

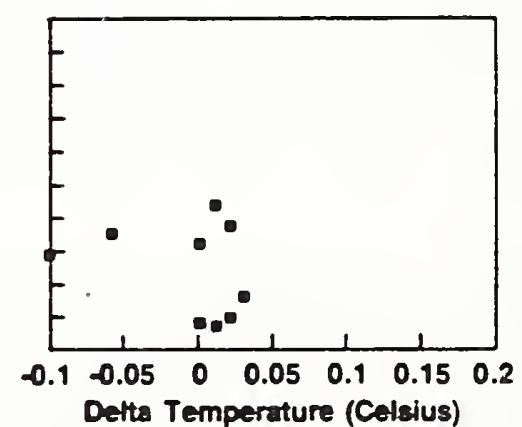


Figure 5. These data illustrate the effects of assumed density on the assigned mass of kilogram A1.
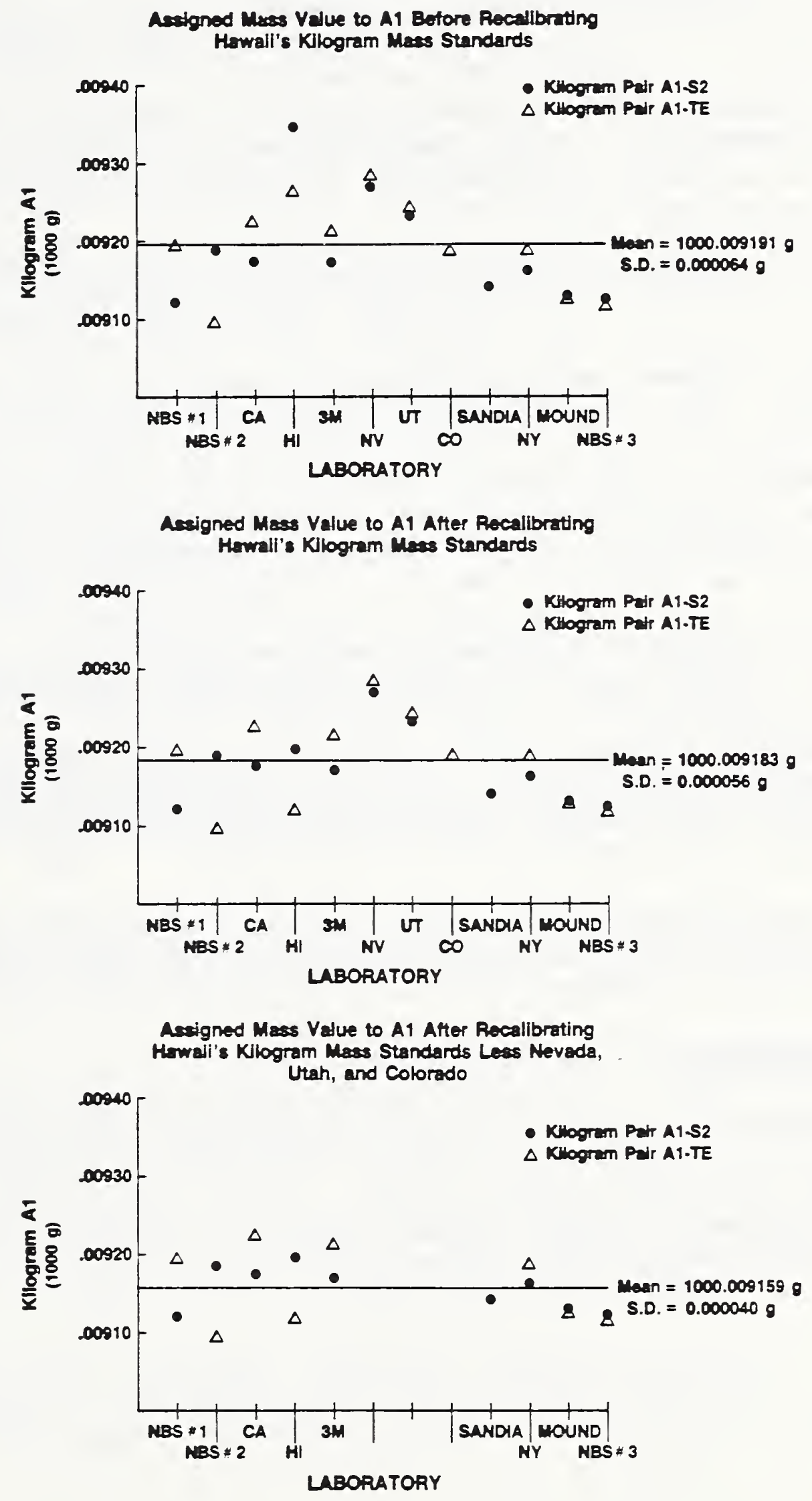
could extend our measurement process to include a summation of 1 kilogram weights $(500 \mathrm{~g}, 300 \mathrm{~g}, 200 \mathrm{~g})$ that have less exaggerated characteristics, without significant systematic errors. This is an important consideration in the calibration of a set of weights if the uncertainty estimates are to be meaningful.

We also note the behavior of kilogram A1 with the data plots of Fig. 5 . Although the kilogram pairing is denoted by dots and triangles it has no significance in this discussion. The above plot includes the Hawaiian point based on a faulty volume assumption and the middle plot with the correct volume. In the lower plot we have removed the data from the states of Colorado, Nevada, and Utah, each with assumed volumes for their standards and used in laboratories at higher elevations and therefore lower air densities than the other laboratories. The standard deviation is not only improved but is very good for routine mass calibrations and we speculate the middle plot would likewise be improved with measured weight volumes used in the data reduction. The New York kilograms, like nearly all state kilograms, have not had their volumes measured and it is probably fortuitous that our data do not reflect a faulty volume assumption. That is, we know the actual material density is somewhat lower than the assumed $8.0 \mathrm{~g} / \mathrm{cm}^{3}$ and that the weights were calibrated and subsequently used at about the same air density thus masking the error. Futhermore the statistical check indicates the New York Kilograms are in need of recalibration and may have some compensating effect for the error. We believe we can use an improved version of this package to calibrate mass standards in the recipient laboratory provided their kilograms have had their densities adequately determined beforehand. Any future effort would be directed toward a complete weight set calibration. Communication with the participants revealed that most, if not all, were pleased with the concept of the package and with the learning experience arising from performing the measurements. Indeed, we believe that NIST successfully transferred near state-of-the-art mass measurement technology to the individuals that participated in the program.

After several years of experience interacting with the state laboratories we believe a program that sponsors the acquisition of computers, software, and electronic instrumentation is needed along with the required support.

\section{Acknowledgements}

We appreciate the funding support provided over the past few years by both Albert Tholen, Chief of the Office of Weights and Measures, and Joe Simmons, our former Division Chief. We are also grateful to Charles Reeve of the Statistical Engineering Division who always provides his statistical advice with good humor. 
1. H. A. Bowman, W. Gallagher, and R. M. Schoonover, "The development of a working density standard," Instrument Society of America, 20th annual ISA conference and exhibit, Oct. 4-7, 1965.

2. P. E. Pontius, "Mass Measurements: A study of anomalies," Science, vol. 190, pp. 379-380, 1975.

3. R. M. Schoonover and J. E. Taylor, "Some recent developments at NBS in mass measurements," IEEE Transactions on Instrumentation and Measurement, vol. IM-35, no. 4, part 1, Dec. 1986.

4. H. A. Bowman and R. M. Schoonover, "Procedure for high precision density determination by hydrostatic weighing," J. Res., vol. 71C, pp. 179-198, July - Aug. 1967.

5. F. E. Jones, "The air density equation and the transfer of the mass unit," J. Res., vol. 10, pp. 419-427, Sept. - Oct. 1978.

6. R. M. Schoonover, R. S. Davis, R. G. Driver, and V. E. Bower, "A practical test of the air density equation in standards laboratories at differing altitudes," J. Res., vol. 85, no. 1, pp 27-38, Jan. - Feb. 1980.

7. R. M. Schoonover, "Advanced mass calibration in state laboratories," Rep. NBSIR 83-2752, pp. 1-9, Aug. 1983.

8. R. M. Schoonover and J. Keller, "A surface dependent thermal effect in mass calibration," in "Report of the 68th National Conference on Weights and Measures 1983," NBS Special Pub. 663, pp. 39-57, 1983.

9. M. E. Cage and R. S. Davis, "An analysis of read-out perturbations seen on an analytical balance with a swinging pan,", J. Res. vol. 87, no. 1, Jan. - Feb. 1982.

10. H. A. Bowman and H. E. Almer, "Minimization of the arrestment error in one-pan, two-knife balance systems," J. Res. Nat. Bur. Stand. (U.S.), 67C (Eng. and Instr.), No. 3, 227-235 (July-Sept. 1963).

11. R. D: Cutkosky and R. S. Davis, "Simple control circuit for temperature regulation and other bridge applications," Rev. Sci. Instrum., vol. 52, no. 9, pp. 1403-1405, Sept. 1981.

12. A. Wexler and S. Hasegawa, "Relative humidity-temperature relationships of some saturated salt solutions in the temperature range $0^{\circ}$ to $50^{\circ} \mathrm{C}, " \mathrm{~J}$. Res., vol. 53, no. 1, July 1954. 
13. M. Kochsiek, "Measurement of Water Adsorption on Metal Surfaces," Metrologia 18, 153-159, 1982. 
Appendices

Appendix I.

Preliminary tape cartridge...................

Appendix II.

Primary tape cartridge...................

Appendix III.

Printout of results.................57 
Appendix I.

In conjunction with the computer, the preliminary tape cartridge is used as a debugging tool during the set up of the data acquisition system. This auxiliary tape, contains the programs TEST and HIST.

TEST is a program that functions as a continuity tester and is used to check the opening and closing of the multiplexer relays before connecting the multiplexer to the remaining components of the data acquisition system.

The program HIST will allow the user to automatically measure temperature, pressure, and relative humidity if the data acquisition system is functioning properly. In addition to using HIST as a diagnostic tool, each laboratory can periodically monitor room temperature and choose the most quiescent period of the day in which to make measurements. 
1030 REM THIS PROGRAM IS A TEST

1040 REM FOR CONTINUITY OF THE

1050 REM 3 RELAYS USED IN THE

1060 REM SECOND ROUND ROBIN.

1070 REM

1080 REM

1090 REM

1100 REM

inItIALIZE

1110 PRINTER IS 2

1120 OPTION BASE 1

1130 INTEGER P2 $(7,5), \mathrm{P} 3(7,5), \mathrm{P} 4(7,5), \mathrm{M}(7,5), \mathrm{T}(7,5)$

1140 INTEGER I, J,N,K

1150 REAL $R(7,5), V, 0, C$

$1160 \quad 0=9000000000$

$1170 \quad C=.4$

$1180 \mathrm{~N}=1$

1190 CLEAR

1200 DISP USING " $2 / "$;

1210 DISP " 1 ) CHECK ALL CONNECTIONS BEFORE"

1220 DISP " RUNNING THIS TEST."

1230 DISP USING "1/" ;

1240 DISP "2) THE PROGRAM IS APPROX.

1250 DISP USING " $1 /$ " ;

1260 DISP "3) RESULTS WILL BE DISPLAYED ON

1270 DISP " TO THE THERMAL PRINTER."

1280 DISP USING " $1 /$ " ;

1290 DISP "4) PRESS THE CONT KEY TO RUN THE TEST."

1300 PAUSE

1310 CLEAR

1320 REM

1330 REM

1340 REM

1350 FOR J=1 TO N

1360 FOR $I=1$ TO 7

$1370 P 2(I, J)=0$

1380 IF $I=2$ THEN $P 2(I, J)=1$

$1390 P 3(I, J)=0$

1400 IF $I=4$ THEN P3 $(I, J)=1$

$1410 P 4(I, J)=0$

1420 IF $I=6$ THEN $P 4(I, J)=1$

1430 NEXT I

1440 NEXT J

1450 REM

1460 REM $\star \star \star$ SET RELAYS

1470 REM

1480 FOR J=1 TO N

1490 FOR $I=1$ TO 7

1500 IF P2(I,J) OR P3(I,J) OR P4 $(I, J)=1$ THEN 1540

1510 OUTPUT $710 ; " \mathrm{Cl}-1-2-3-4-5-6-7-8 "$

1520 GOSUB 1790

1530 GOTO 1730

1540 IF $P 2(I, J)=0$ THEN 1580

1550 OUTPUT $710 ; " \mathrm{Cl}+2-3-4 "$

1560 GOSUB 1790

1570 GOTO 1730

5 MINUTES LONG."

THE SCREEN AND/OR OUTPUT"

1580 IF $P 3(I, J)=0$ THEN 1620

1590 OUTPUT $710 ; " \mathrm{Cl}-2+3-4$ " 
1600 GOSUB 1790

1610 GOTO 1730

1620 IF $P 4(I, J)=0$ THEN 1660

1630 OUTPUT $710 ; " \mathrm{Cl}-2-3+4 "$

1640 GOSUB 1790

1650 GOTO 1730

1660 CLEAR

1670 DISP USING " $4 /$ ";

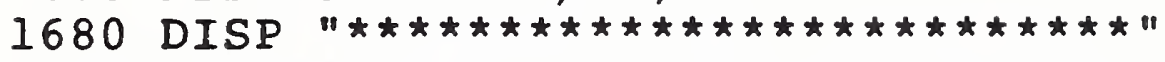

1690 DISP "PROGRAM ERROR!! ALL PORTS ARE OPEN."

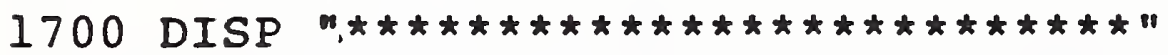

1710 BEEP \& BEEP \& BEEP \& BEEP \& BEEP

1720 PAUSE

1730 NEXT I

1740 NEXT J

1750 GOTO 1930

1760 REM

1770 REM *** READ METER ***

1780 REM

1790 WAIT 3000

1800 OUTPUT $724 ; " F 3 R A N 4 T 2 "$

$1810 R(I, J)=0$

1820 FOR $\mathrm{K}=1$ TO 10

1830 WAIT 300

1840 TRIGGER 724 .

1850 ENTER $724 ; \mathrm{V}$

$1860 R(I, J)=R(I, J)+V$

1870 NEXT $K$

$1880 \mathrm{R}(I, J)=\mathrm{R}(\mathrm{I}, \mathrm{J}) / 10$

1890 RETURN

1900 REM

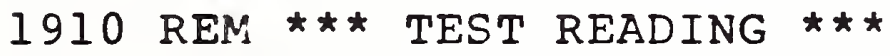

1920 REM

1930 FOR J=1 TO N

1940 FOR $I=1$ TO 7

1950 IF $R(I, J)>C$ THEN $M(I, J)=0$

1960 IF $R(I, J)<0$ THEN $M(I, J)=1$

1970 IF $R(I, J)>=C$ AND $R(I, J)<=0$ THEN $M(I, J)=10$

1980 ON I GOTO 1990,2010,1990,2010,1990,2010,1990

1990 IF $M(I, J)=0$ THEN $T(I, J)=0 \quad \operatorname{ELSE} \quad T(I, J)=1$

2000 GOTO 2020

2010 IF $M(I, J)=1$ THEN $T(I, J)=0 \quad \operatorname{ELSE} \quad T(I, J)=1$

$2020 \operatorname{IF} R(I, J)>=C$ AND $R(I, J)<=0$ THEN $T(I, J)=1$

2030 NEXT I

2040 NEXT J

2050 REM

2060 REM *** RESULTS ***

2070 REM

2080 FOR J=1 TO N

2090 FOR $I=1$ TO 7

2100 IF $T(I, J)=1$ THEN GOTO 2190

2110 NEXT I

2120 NEXT J

2130 CLEAR

2140 DISP USING "6/" ;

2150 DISP "THE MULTIPLEXER RELAYS ARE IN"

2160 DISP " GOOD WORKING ORDER."

2170 BEEP \& BEEP

2180 GOTO 2420

2190 CLEAR 
2200 DISP USING " $4 / "$;

2210 DISP "WARNING!!!!!!!!!!!"

2220 DISP USING " $1 /$ " ;

2230 DISP "THE MULTIPLEXER RELAYS HAVE

FAILED THE CONTINUITY TEST."

2240 DISP "PLEASE EXAMINE ALL ELECTRICAL

(S) IS FAULTY."

2250 BEEP \& BEEP \& BEEP \& BEEP \& BEEP

2260 PRINT USING " $2 /$ " ;

2270 FOR $\mathrm{J}=1$ TO $\mathrm{N}$.

2280 PRINT "N="; J

2290 FOR $I=1$ TO 7

2300

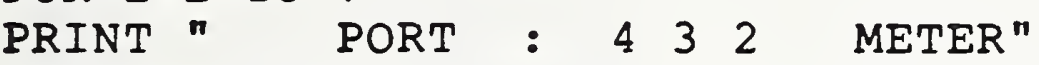

CONNECTIONS OR DETERMINE WHICH RELAY

PRINT USING $2320 ; P 4(I, J), P 3(I, J), P 2(I, J), M(I, J)$

IMAGE $4 \mathrm{X}$, "VALUE $: ", 2 \mathrm{X}, 3(\mathrm{D}, \mathrm{X}), 3 \mathrm{X}, \mathrm{DD}$

IF $T(I, J)=1$ THEN GOSUB 2390

PRINT USING " $2 /$ " ;

NEXT I

PRINT USING " $3 /$ " ;

NEXT J

GOTO 2420

PRINT USING $2400 ; R(I, J)$

IMAGE $\mathrm{X}, \mathrm{V}=\mathrm{N}, \mathrm{K}, \mathrm{X}$, "OHMS"

RETURN

END 
1030 REM PROGRAM WILL AUTOREAD

1040 REM ENVIROMENTAL DATA,

1050 REM TIME, AND DATE.

1060 REM

1070 REM VALUES ARE OUTPUT TO

1080 REM THE THERMAL PRINTER.

1090 REM

1100 REM TIME INTERVALS ARE

1110 REM INPUT IN HOURS.

1120 REM

1130 REM

1140 PRINTER IS 2

1150 OPTION BASE 1

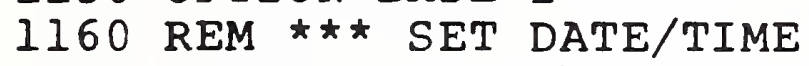

1170 CLEAR

1180 DISP USING " $3 /$ " ;

1190 DISP "INPUT THE CURRENT DATE USING THE FOLLOWING FORMAT:"

1200 DISP USING " $1 /$ " ;

1210 DISP " $\mathrm{XX} / \mathrm{XX} / \mathrm{XXXX"}$

1220 DISP USING " $1 /$ " ;

1230 DISP " EXAMPLE: 04/05/1986"

1240 INPUT AS

1250 A $=$ MDY (A\$)-MDY ( $01 / 01 / 1985 ")$

1260 CLEAR

1270 DISP USING " $3 /$ " ;

1280 DISP "INPUT THE CURRENT MILITARY TIME USING THE FOLLOWING FORMAT:"

1290 DISP USING " $1 /$ " ;

1300 DISP " HH:MM:SS"

1310 DISP USING "1/" ;

1320 DISP " EXAMPLE: 14:07:00"

1330 INPUT BS

1340 SETTIME HMS (B\$), A

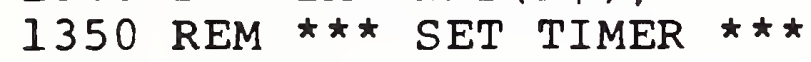

1360 CLEAR

1370 DISP USING " $3 /$ " ;

1380 DISP "INPUT TIME INTERVAL (HRS)."

1390 INPUT HI

$1400 \mathrm{HI}=3600000 \star^{\mathrm{HI}}$

1410 CLEAR

1420 GOTO 1460

1430 ON TIMER\# 1,HI GOTO 1460

1440 GOTO 1440

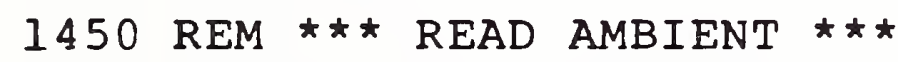

1460 OUTPUT $724 ; "$ "FlRAN5T2"

1470 OUTPUT $710 ; " \mathrm{Cl}-1+2-3-4-5-6-7-8$ "

1480 GOSUB 1600

1490 ENTER $724 ; \mathrm{T}$

$1500 \mathrm{~T}=84.02531 * \mathrm{~T}-.101$

1510 OUTPUT $710 ; " \mathrm{Cl}-1-2+3-4-5-6-7-8$ "

1520 GOSUB 1600

1530 ENTER $724 ; P$

$1540 \mathrm{P}=(30 * \mathrm{P}+800) / 1.333224$

1550 OUTPUT $710 ; " \mathrm{Cl}-1-2-3+4-5-6-7-8$ "

1560 GOSUB 1600

1570 ENTER $724 ; \mathrm{H}$

$1580 \mathrm{H}=\mathrm{H} / .02-2.5$

1590 GOTO 1640 
1600 WAIT 2000

1610 TRIGGER 724

1620 RETURN

1630 REM $\star * \star$ PRINT DATA $* \star *$

1640 PRINT USING " $2 /$ " ;

1650 PRINT MDY \$(DATE+MDY("01/01/1985"))

1660 PRINT TIME\$

1670 PRINT USING $1680 ; T$

680 IMAGE " $T=", M 3 D Z .2 \mathrm{D}$

690 PRINT USING $1700 ; P$

.700 IMAGE '" $P=", M 3 D Z .2 D$

.710 PRINT USING $1720 ; \mathrm{H}$

.720 IMAGE " $\mathrm{H}=", M 3 \mathrm{DZ} .1 \mathrm{D}$

1730 OFF TIMER\# 1

1740 GOTO 1430

1750 END 
Appendix II .

Each participating laboratory receives a duplicate copy of the primary tape cartridge with which weighings can be recorded, analyzed, and then returned to the NIST for a group comparison. This cartridge has one central program, seven subprograms, and three data files, table 3 in the main text. The three data files (A MAIN, B MAIN, and C MAIN) are storage areas in which all of the information associated with three sets of weighings ( $A 1-\mathrm{S} 2, \mathrm{R} 2-\mathrm{H} 2$, and $\mathrm{A} 1-\mathrm{TE}$ ) are saved and modified by the various subprograms.

The main program "Autost" and its subprograms follow the logic outlined in Fig. 1. Whereby the user first selects a storage area (data file)

followed by one of three processes (subprograms):

1. Input data using subprograms INPUT or MEASUR,

2. Revise the data file using subprogram EDITD, or

3. Compute and assign true mass values to the four kilograms associated with

this data file using subprograms ANALY and SUBRHO.

The following is a brief description of the program files found on this tape cartridge:

Autost - The central program from which access to subprograms are obtained whenever necessary. As its name implies, the computer will automatically start executing commands from this program as soon as the user turns on power to the computer, provided the tape cartridge is in place.

INPUT - This subprogram allows the user to enter constants (the known standard deviation of the balance, volumetric coefficient of thermal expansion of the standard, etc.) from the keyboard into a data file.

MEASUR - Used to store, in a data file, balance readings and environmental conditions obtained in situ.

EDITD - An editor which allows the user to modify the data file whenever necessary.

ANALY - Contains the algorithm used to assign mass values to each kilogram and provide the user with a hard copy of results using the 80 -column printer.

SUBRHO - Calculates an air density using temperature, pressure, and relative humidity values imported from subprogram ANALY.

PRINTM - A subprogram which will print the contents of a data file.

TRANSD - Although this program is not used during the weighings, it was written to be used as a mechanism through which data files can be transferred to and from tape cartridges. 
Figure 1. Software flowchart.

1) LOAD AND RUN PROGRAM "Autost."

2) SELECT ONE OF THE THREE DATA FILES CORRESPONDING TO WEIGHING SERIES A1-S2, R2-H2, OR A1-TE.

3) USING SUBPROGRAM "INPUT," RECORD CONSTANT PARAMETERS OF THE WEIGHING SERIES INTO THE DATA FILE.

4) USING "MEASUR," RECORD BALANCE OBSERVATIONS AND AIR DENSITY READINGS INTO THE DATA FILE.

5) IF NECESSARY, MODIFY THE DATA FILE WITH "EDITD."

6) COMPUTE THE BOUYANCY CORRECTIONS AND MASS FOR EACH KILOGRAM USING "SUBRHO" AND "ANALY."

RESULTS ARE DISPLAYED WITH THE 80.COLUMN PRINTER AND "PRINTM" WILL LIST THE CONTENTS OF THE DATA FILE.

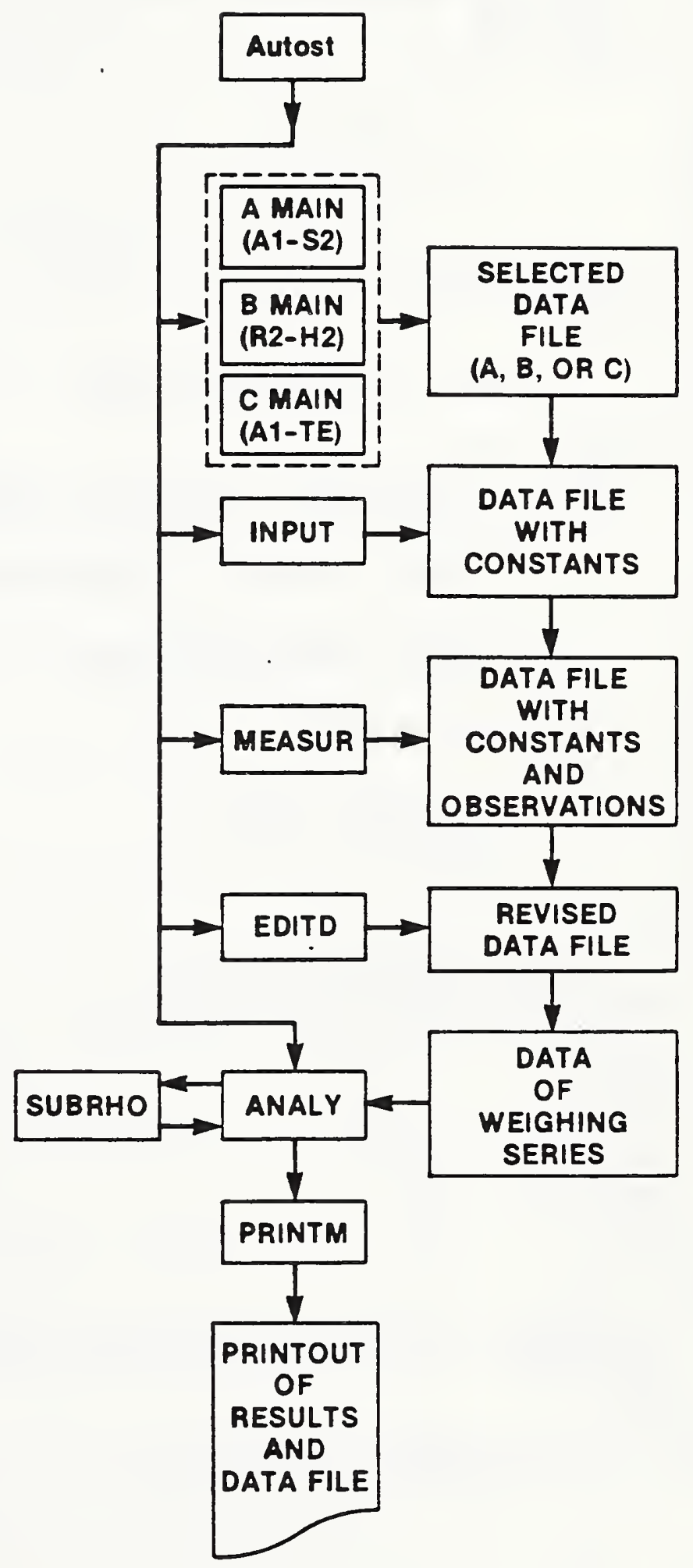


100 REM *MAIN PROGRAM

110 REM

120 REM *CONTROLLER FOR TRUE

130 REM MASS WEIGHINGS IN FOUR

140 REM /ONE'S SERIES.

150 REM

160 REM *WRITTEN BY J TAYLOR,

170 REM FOR OWM $3 / 85$.

180 REM

790 CLEAR

200 PRINTER IS 701,80

210 DISP USING " $2 /$ "

220 DISP "TYPE IN MESUREMENT PAIR AS"

230 DISP "FOLLOWS :"

240 DISP USING " $2 /$ "

250 DISP " $\quad 1=$ AI S2"

260 DISP

270 DISP " $2=\mathrm{R} 2 \mathrm{H} 2 "$

280 DISP

290 DISP " $\quad 3=A I$ TE"

300 DISP USING " $2 /$ "

310 INPUT $X 7$

320 IF $X 7<1$ OR $X 7>3$ THEN GOTO 190

330 CLEAR

340 DISP USING " $2 /$ "

350 DISP "TYPE IN DESIRED PROGRAM FUNCTION AS FOLLOWS:" 360 DISP "

370 DISP " 1 = INPUT SYSTEM PARAMETERS."

380 DISP "

390 DISP " 2 = INPUT MEASUREMENTS."

400 DISP "

410 DISP "

420 DISP "

430 DISP " 4 = ANALYZE DATA."

440 DISP

450 DISP " $5=$ END"

460 INPUT $X$

470 IF $X<1$ OR $X>5$ THEN GOTO 330

480 ON X GOTO $490,510,530,550,590$

490 CALL "INPUT" ( X7)

500 GOTO 330

510 CALL "MEASUR" ( X7)

520 GOTO 330

530 CALL "EDITD" ( $\times 7)$

540 GOTO 330

550 CLEAR

560 CALL "ANALY" ( $X 7)$

570 CALL "PRINTM" ( $X 7)$

580 GOTO 330

590 CLEAR @ DISP USING " $6 / "$

600 DISP " RUN TERMINATED."

610 END 
30 REM *INPUTS DATA FROM KEY-

40 REM BOARD TO MAIN

50 REM DATA FILES.

60 REM

70 REM *WRITTEN BY J TAYLOR

80 REM FOR OWM $3 / 85$.

90 REM

100 OPTION BASE 1

110 DIM H2\$[20], H3\$[8]

120 ON X7 GOTO $130,150,170$

130 ASSIGN\# 1 TO "A MAIN"

140 GOTO 180

150 ASSIGN\# 1 TO "B MAIN"

160 GOTO 180

170 ASSIGN\# 1 TO "C MAIN"

180 CLEAR

190 DISP

200 DISP "TYPE IN DESIRED PROGRAM FUNCTION AS FOLLOWS:"

210 DISP

220 DISP " 1 = INPUT HEADING/DATE."

230 DISP

240 DISP " 2 = INPUT CONSTANT DATA."

250 DISP

260 DISP " $3=$ EXIT"

270 DISP

280 INPUT $K$

290 IF $K<1$ OR $K>3$ THEN GOTO 180

300 ON K GOTO $320,430,1270$

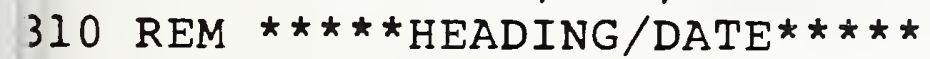

320 CLEAR

$330 \mathrm{~N}=2$

$340 \mathrm{H} 2 \$="$

350 DISP "INPUT HEADING ( 20 CHARACTERS"

360 DISP "MAX)."

370 INPUT H2\$

380 DISP "INPUT DATE $(\mathrm{XX} / \mathrm{XX} / \mathrm{XX})$."

390 INPUT H $3 \$$

100 PRINT\# 1,$1 ; N, H 2 \$, H 3 \$$

110 GOTO 180

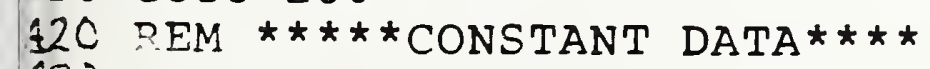

130 . $\triangle E A R$

140 DISP "INPUT KNOWN MASS OF WGHT\# I (MG)."

$\$ 50$ INPUT AI

160 DISP "INPUT KNOWN MASS OF WGHT\#2 (MG)."

170 INPUT BI

180 DISP "INPUT THE STANDARD DEVIATION OF THE BALANCE(MG)."

190 INPUT $\mathrm{Cl}$

;00 DISP "INPUT THE MASS OF THE SENSITI-"

¡10 DISP "VITY WGHT. (MG)."

;20 INPUT DI

;30 DISP "INPUT THE VOLUME OF THE SENSITI-"

;40 DISP "VITY WGHT. (CC)."

;50 INPUT E1

;60 DISP "INPUT TEMPERATURE CORRECTION"

;70 DISP "(DEG C)."

i80 INPUT FI

;90 DISP "INPUT PRESSURE CORRECTION" , 00 DISP "(MM HG)." 
610 INPUT GI

620 DISP "INPUT HUMIDITY CORRECTION ( 8$). "$

630 INPUT HI

640 PRINT\# 1,2 ; $A 1, B l, C l, D l, E l, F l, G l, H l$

650 DISP "INPUT COEF. OF THERM. EXPANSION OF WGHT\# $1 . "$

660 INPUT A2

670 DISP "INPUT VOLUME OF WGHT\#I (CC)."

680 INPUT B2

690 DISP "INPUT DENSITY OF WGHT\# I (G/CC)."

700 INPUT C2

710 DISP "INPUT MASS OF ADDED WEIGHT TO"

720 DISP "WGHT\# I (MG)."

730 INPUT D2

740 DISP "INPUT COẸF. OF THERM. EXPANSION OF THE ADDED WEIGHT."

750 INPUT E2

760 DISP "INPUT VOLUME OF ADDED WEIGHT"

770 DISP "(CC)."

780 INPUT F2

790 PRINT\# 1,3 ; A2,B2,C2,D2,E2,F2

800 DISP "INPUT COEF. OF THERM. EXPANSION OF WGHT\# 2 ."

810 INPUT A3

820 DISP "INPUT VOLUME OF WGHT\#2 (CC)."

830 INPUT B3

840 DISP "INPUT DENSITY OF WGHT\#2 (G/CC)."

850 INPUT $C 3$

860 DISP "INPUT MASS OF ADDED WEIGHT TO"

870 DISP "WGHT\#2 (MG)."

880 INPUT D3

890 DISP "INPUT COEF. OF THERM. EXPANSION OF ADDED WEIGHT."

900 INPUT E3

910 DISP "INPUT VOLUME OF ADDED WEIGHT"

920 DISP " (CC)."

930 INPUT F3

940 PRINT\# 1,$4 ; A 3, B 3, C 3, D 3, E 3, F 3$

950 DISP "INPUT COEF. OF THERM. EXPANSION OF WGHT\#3."

960 INPUT A4

970 DISP "INPUT VOLUME OF WGHT\#3 (CC)."

980 INPUT B4

990 DISP "INPUT DENSITY OF WGHT\#3 (G/CC)."

1000 INPUT C4

1010 DISP "INPUT MASS OF ADDED WEIGHT TO"

1020 DISP "WGHT\# 3 (MG)."

1030 INPUT D4

1040 DISP "INPUT COEF. OF THERM. EXPANSION OF ADDED WEIGHT."

1050 INPUT E4

1060 DISP "INPUT VOLUME OF ADDED WEIGHT"

1070 DISP "(CC)."

1080 INPUT F4

1090 PRINT\# 1,$5 ; \mathrm{A} 4, \mathrm{~B} 4, \mathrm{C} 4, \mathrm{D} 4, \mathrm{E} 4, \mathrm{~F} 4$

1100 DISP "INPUT COEF. OF THERM. EXPANSION OF WGHT\#4."

1110 INPUT A5

1120 DISP "INPUT VOLUME OF WGHT\#4 (CC)."

1130 INPUT B5

1140 DISP "INPUT DENSITY OF WGHT\# 4 (G/CC)."

1150 INPUT C5

1160 DISP "INPUT MASS OF ADDED WEIGHT TO"

II70 DISP "WGHT\# 4 (MG)."

1180 INPUT D5

1190 DISP "INPUT COEF. OF THERM. EXPANSION OF ADDED WEIGHT." 1200 INPUT E5 
1210 DISP "INPUT VOLUME OF ADDED WEIGHT"

1220 DISP "(CC)."

1230 INPUT F5

1240 PRINT\# 1,$6 ; \mathrm{A} 5, \mathrm{~B} 5, \mathrm{C} 5, \mathrm{D} 5, \mathrm{E} 5, \mathrm{~F} 5$

1250 GOTO 180

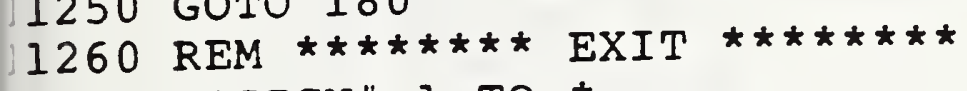

1270 ASSIGN\# 1 TO $\star$

1280 SUBEND 
100 SUB "MEASUR" ( $X 7)$

110 REM

120 REM *RECORDS BALANCE

130 REM OBSERVATIONS FROM

140 REM THE KEYBOARD.

150 REM

160 REM *RECORDS VOLTMETER

170 REM READINGS OF TEMP,

180 REM PRESS, AND REL HUMD.

190 REM

200 REM *WRITTEN BY J TAYLOR

210 REM FOR OWM $3 / 85$.

220 REM

230 OPTION BASE 1

240 DIM $T(6,5), P(6,5), H(6,5), O(6,4), T 2(6), P 2(6), H 2(6)$

250 DIM M\$[5],X\$[2], Z\$[13], Y\$[2],W\$[3]

260 ON X7 GOTO $270,290,310$

270 ASSIGN\# I TO "A MAIN"

280 GOTO 320

290 ASSIGN\# I TO "B MAIN"

300 GOTO 320

310 ASSIGN\# I TO "C MAIN"

320 PRINTER IS 2

$330 \quad 2 \$="$ INPUT OBSER "

$340 \mathrm{~W} \$="+"$

350 ON KEY\# 1,"MI:M2" GOTO 490

360 ON KEY\# 2,"MI:M3" GOTO 510

370 ON KEY\# 3,"MI:M4" GOTO 530

380 ON KEY\# 5,"M2:M3" GOTO 550

390 ON REY\# 6,"M2:M4" GOTO 570

400 ON KEY\# 7,"M3:M4" GOTO 590

410 ON KEY\# 8,"EXIT" GOTO 1080

420 CLEAR @ KEY LABEL

430 DISP USING " $4 /$ "

440 DISP " DEPRESS ANY OF THE"

450 DISP " LABELED KEYS BELOW TO"

460 DISP " OBTAIN THE DESIRED"

470 DISP " MEASURMENT FUNCTION."

480 GOTO 480

$490 \mathrm{M} \$=" M I: M 2 "$ \& $I=I$ \& $\$=" M I "$ e $Y \$=" M 2 "$

500 GOTO 600

$510 \mathrm{M} \$=" M I: M 3 "$ \& $I=2$ \& $\$=" M I "$ \& $\$=" M 3 "$

520 GOTO 600

$530 \mathrm{M} \$=" M I: M 4 "$ \& $I=3$ @ $X \$=" M I "$ \& $Y=" M 4 "$

540 GOTO 600

$550 M \$=" M 2: M 3 "$ e $I=4$ \& $X \$=" M 2 "$ \& $Y \$=" M 3 "$

560 GOTO 600

$570 \mathrm{M} \$=$ "M2:M4" \& $I=5$ \& $X \$=" M 2 "$ e $Y \$=" M 4 "$

580 GOTO 600

$590 \mathrm{M} \$=" M 3: M 4 n$ \& $I=6$ \& $X \$=" M 3 "$ \& $Y \$=" M 4 "$

600 CLEAR \& REY LABEL

610 DISP HGL\$(M\$) \& PRINT HGL\$(M\$)

620 PRINT USING "/"

$630 Q=1$ \& GOSUB 930

640 DISP Z\$;X\$

650 INPUT $O(I, I)$

660 DISP Z\$; Y\$

670 INPUT $O(I, 2)$

680 DISP Z\$;Y\$; W\$

690 INPUT $O(I, 3)$ 
700 DISP Z\$; $X \$$; $\$$

710 INPUT $O(I, 4)$

$720 \mathrm{Q}=2$ Q GOSUB 930

$730 \mathrm{TI}=0$ \& $\mathrm{PI}=0$ \& $\mathrm{HI}=0$

740 FOR $Q=1$ TO 2

$750 \quad \mathrm{Tl}=\mathrm{TI}+\mathrm{T}(\mathrm{I}, \mathrm{Q})$

$760 \quad \mathrm{Pl}=\mathrm{Pl}+\mathrm{P}(I, \mathrm{Q})$

$770 \quad \mathrm{BI}=\mathrm{B} I+\mathrm{B}(I, Q)$

780 NEXT $Q$

$790 \mathrm{Tl}=\mathrm{Tl} / 2$ \& $\mathrm{Pl}=\mathrm{Pl} / 2$ \& $\mathrm{HI}=\mathrm{HI} / 2$

$800 \mathrm{~T} 2(I)=84.02531 * \mathrm{~T} 1-.101$

$810 \quad P 2(I)=(30 * P I+800) / 1.333224$

$820 \mathrm{H} 2(I)=\mathrm{HI} / .02-2.5$

830 FOR $J=1$ TO 4

840 PRINT $O(I, J)$

850 NEXT $\mathrm{J}$

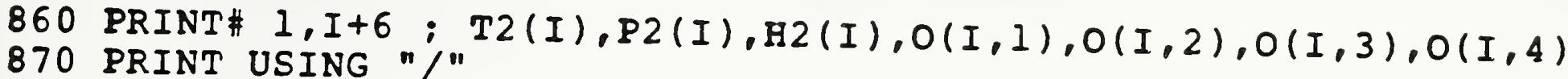

880 PRINT USING " $4 \mathrm{~A}, 2 \mathrm{D} .3 \mathrm{D}^{n} ; " \mathrm{~T}=\mathrm{m}, \mathrm{T} 2(\mathrm{I})$

890 PRINT USING " $4 A, 3 D .3 D " ; " \quad P=", P 2(I)$

900 PRINT USING " $4 \mathrm{~A}, 2 \mathrm{D} .2 \mathrm{D} " ; " \mathrm{H}=$ ", $\mathrm{H} 2$ (I)

910 PRINT USING " $2 / "$

920 GOTO 420

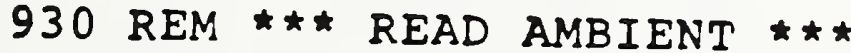

940 OUTPUT 724 :"FIRAN5T2"

950 OUTPUT $710 ; " \mathrm{Cl}-1+2-3-4-5-6-7-8$ "

960 GOSUB 1050

970 ENTER 724 : $T(I, Q)$

980 OUTPUT $710 ; " \mathrm{Cl}-1-2+3-4-5-6-7-8$ "

990 GOSUB 1050

1000 ENTER $724 ; P(I, Q)$

1010 OUTPUT $710 ; " \mathrm{Cl}-1-2-3+4-5-6-7-8$ "

1020 GOSUB 1050

1030 ENTER $724 ; H(I, Q)$

1040 RETURN

1050 WAIT 2000

1060 TRIGGER 724

1070 RETURN

1080 PRINTER IS 701,80

1090 ASSIGN\# 1 TO *

1100 SUBEND 


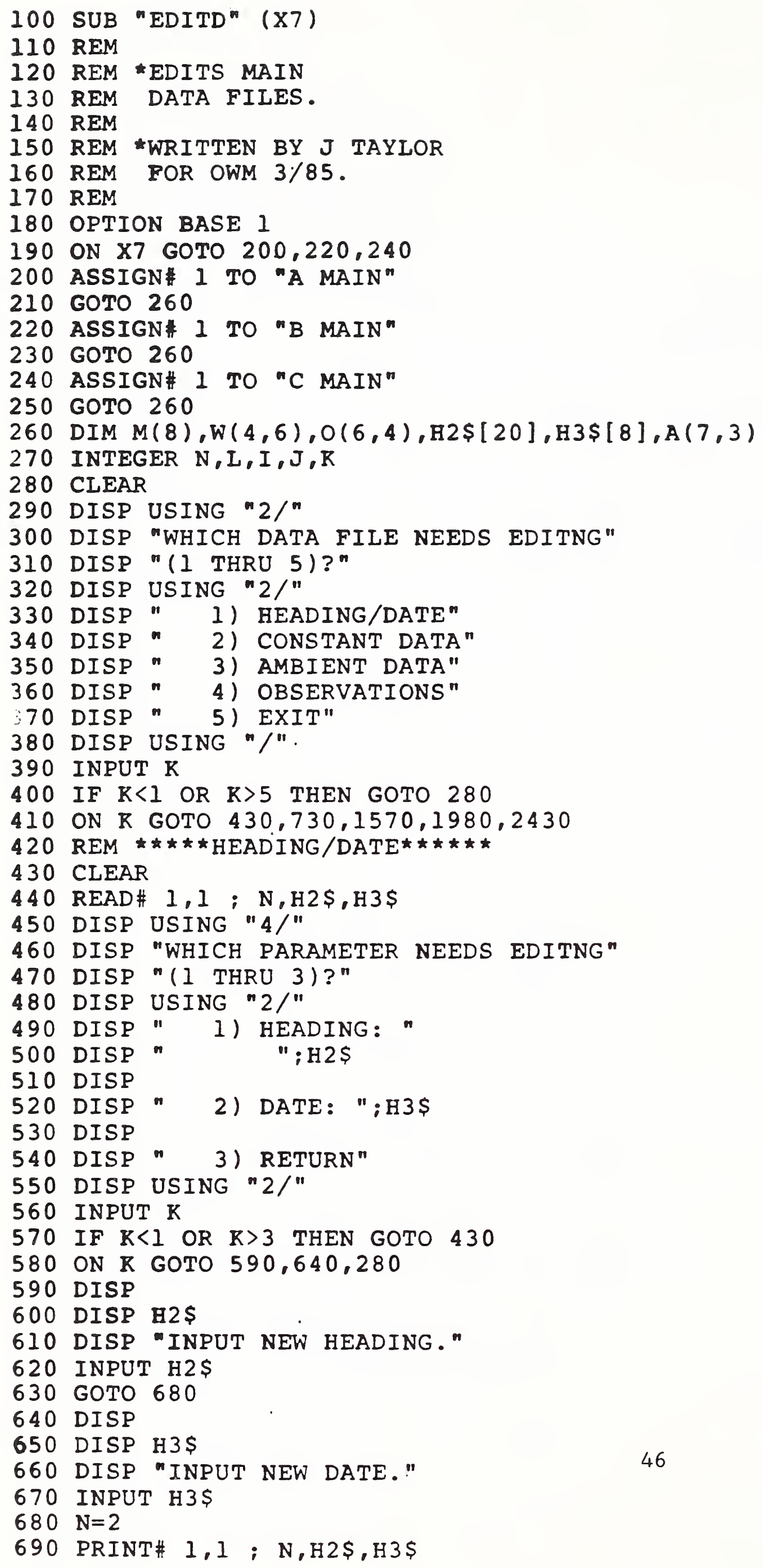


700 READ\# 1,$1 ; \mathrm{N}, \mathrm{H} 2 \$, \mathrm{H} 3 \$$

710 GOTO 430

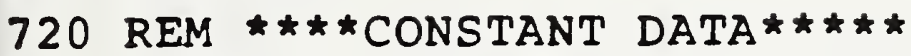

730 CLEAR $Q$ CRT OFF

740 READ\# 1,$2 ; M(1), M(2), M(3), M(4), M(5), M(6), M(7), M(8)$

750 FOR $I=1$ TO 4

760 READ\# $1, I+2 ; W(I, I), W(I, 2), W(I, 3), W(I, 4), W(I, 5), W(I, 6)$

770 NEXT I

780 CRT ON

790 CLEAR

800 DISP USING "/"

810 DISP "WHICH GROUPING NEEDS EDITING"

820 DISP "(1 THRU 6)?"

830 DISP USING "/"

840 DISP " 1) STANDARDS/SENSITIVITY /"

850 DISP " INSTR. CORREC."

860 DISP " 2) WEIGHT \#I"

870 DISP " 3) WEIGHT \#2"

880 DISP " 4) WEIGHT \#3"

890 DISP " 5) WEIGHT \#4"

900 DISP " 6) RETURN"

910 DISP USING "/"

920 INPUT $\mathrm{K}$

930 IF $K<I$ OR $R>6$ THEN GOTO 790

940 ON K GOTO $950,1240,1240,1240,1240,280$

950 CLEAR

960 DISP USING " $3 /$ "

970 DISP " WHICH PARAMETER NEEDS EDITNG"

980 DISP " (I THRU 9)?"

990 DISP USING "/"

1000 DISP USING 1010 ; "I) MASS WT\# 1 (MG): "M(I)

1010 IMAGE $19 \mathrm{~A}, \mathrm{~K}$

1020 DISP USING 1030 ; "2) MASS WT\#2 (MG): "M(2)

1030 IMAGE 19A,K

1040 DISP "3) BALANCE S.D. (MG): ";M(3)

1050 DISP "4) MASS SEN WT (MG):";M(4)

1060 DISP "5) VOL SEN WT (MG): ";M(5)

1070 DISP "6) TEMP CORREC (DEG C): ";M(6)

1080 DISP "7) PRESS CORREC (MM HG): "; $M(7)$

1090 DISP "8) HUM CORREC (\&): ";M(8)

1100 DISP "9) RETURN"

1110 DISP USING "/"

1120 INPUT $\mathrm{K}$

1130 IF $K<1$ OR $R>9$ THEN GOTO 950

1140 IF $\mathrm{K}=9$ THEN GOTO 790

1150 DISP

1160 DISP $M(K)$

1170 DISP "INPUT NEW VALUE."

1180 INPUT $M(K)$

1190 CRT OFF

1200 PRINT\# 1,$2 ; M(1), M(2), M(3), M(4), M(5), M(6), M(7), M(8)$

1210 READ\# 1,$2 ; M(1), M(2), M(3), M(4), M(5), M(6), M(7), M(8)$

1220 CRT ON Q CLEAR

1230 GOTO 950

$1240 \mathrm{~K}=\mathrm{K}-1$

1250 CLEAR

1260 DISP USING " $3 /$ "

1270 DISP "WHICH PARAMETER NEEDS EDITING"

1280 DISP "( 1 THRU 7 )?"

1290 DISP USING " $2 /$ " 
1300 DISP USING $1310 ; " 1)$ THERM COEF WT\#", $R, n: " W(R, I)$

1310 IMAGE $X, 17 A, K, A, X, R$

1320 DISP USING $1330 ; " 2)$ VOI OF WT\#", $R, n: n, W(R, 2)$

1330 IMAGE $X, 13 A, K, A, X, R$

1340 DISP USING $1350 ; " 3)$ DEN OF WT\#", $K, n: ", W(R, 3)$

1350 IMAGE $X, 13 A, R, A, X, R$

1360 DISP USING $1370 ; " 4)$ MASS OF ADD WT:" $W(R, 4)$

1370 IMAGE $X, 18 \mathrm{~A}, \mathrm{X}, \mathrm{K}$

1380 DISP USING 1390 ; "5) THERM COEF ADD WT:",W(K,5)

1390. IMAGE $X, 21 A, X, R$

1400 DISP USING 1410 ; "6) VOI OF ADD WT:",W(R,6)

1410 IMAGE $X, 17 \mathrm{~A}, \mathrm{X}, \mathrm{K}$

1420 DISP " 7) RETURN"

1430 DISP USING "/"

1440 INPUT I

1450 IF $I<I$ OR $I>7$ THEN GOTO 1260

1460 IF $\mathrm{I}=7$ THEN GOTO 790

1470 DISP

1480 DISP $W(K, L)$

1490 DISP "INPUT NEW VALUE"

1500 INPUT $W(K, I)$

1510 CRT OFF \& CLEAR

1520 PRINT\# $1, K+2 ; W(K, 1), W(K, 2), W(K, 3), W(K, 4), W(K, 5), W(K, 6)$

1530 READ\# $1, K+2 ; W(K, 1), W(K, 2), W(K, 3), W(K, 4), W(K, 5), W(K, 6)$

1540 CRT ON

1550 GOTO 1250

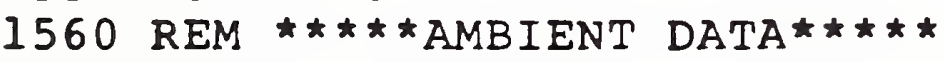

1570 CLEAR \& CRT OFF

1580 FOR $I=1$ TO 6

1590 READ\# $1, I+6 ; A(I, I), A(I, 2), A(I, 3), O(I, I), O(I, 2), O(I, 3), O(I, 4)$

1600 NEXT I

1610 CRT ON

1620 CLEAR

1630 DISP USING "2/"

1640 DISP "WHICH DATA POINT NEEDS EDITING"

1650 DISP "( 1 THRU 7)?"

1660 DISP USING "/"

1670 T\$=HGL\$ ("T")

1680 P\$=HGL $(" P ")$

1690 R\$=HGL $\$$ ("RH")

1700 DISP USING $1710 ; \mathrm{T} \$, P \$, R \$$

1710 IMAGE $8 X, A, 7 X, A, 6 X, 2 A, 2 /$

1720 FOR $I=1$ TO 6

1730 DISP USING $1740 ; I, ") ", A(I, I), A(I, 2), A(I, 3)$

1740 IMAGE $2 X, K, A, 2 X, D Z, 2 D, 2 X, 2 D Z .3 D, 2 X, D Z . D$

1750 NEXT I

1760 DISP USING "/"

1770 DISP " 7) RETURN"

1780 INPUT $R$

1790 IF $\mathrm{K}<1$ OR $\mathrm{K}>7$ THEN GOTO 1620

1800 IF $\mathrm{K}=7$ THEN GOTO 280

1810 DISP

1820 DISP USING $1830 ; K, ") ", A(K, I), A(K, 2), A(K, 3)$

1830 IMAGE $X, K, A, X, K, 4 X, K, 4 X, K$

1840 DISP "WHICH VALUE NEEDS EDITING"

1850 DISP " $(1,2,3)$ ?"

1860 INPUT L

1870 IF $\mathrm{L}<1$ OR L>3 THEN GOTO 1810

1880 DISP

1890 DISP $A(K, I)$ 
1900 DISP "INPUT NEW VALUE"

1910 INPUT $A(K, L)$

1920 CRT OFF

1930 PRINT\# $1, K+6 ; A(K, 1), A(K, 2), A(K, 3), O(K, 1), O(K, 2), O(K, 3), O(K, 4)$

1940 READ\# $1, R+6 ; A(R, 1), A(K, 2), A(R, 3), O(R, 1), O(K, 2), O(K, 3), O(K, 4)$

$1950 \mathrm{CRT}$ ON $\mathrm{C}$ CLEAR

1960 GOTO 1630

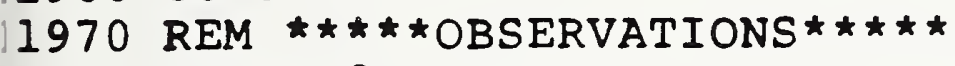

1980 CLEAR \& CRT OFF

1990 FOR $I=1$ TO 6 .

2000 READ $1, I+6 ; A(I, 1), A(I, 2), A(I, 3), O(I, 1), O(I, 2), O(I, 3), O(I, 4)$

2010 NEXT I

2020 CRT ON

2030 CLEAR

2040 DISP USING "/"

2050 DISP "WHICH COMPARISON NEEDS EDITING"

2060 DISP "( 1 THRU 7)?"

2070 DISP USING "/"

2080 DISP " 1) WGHT\# 1 - WGHT\# 2"

2090 DISP " 2) WGHT\#I - WGHT\#3"

2100 DISP " 3) WGHT\#I - WGHT\#4"

2110 DISP " 4) WGHT\#2 - WGHT\#3"

2120 DISP " 5) WGHT\#2 - WGHT\#4"

2130 DISP " 6) WGHT\# 3 - WGHT\#4"

2140 DISP " 7) RETURN"

2150 DISP USING "/"

2160 INPUT $K$

2170 IF $K<1$ OR K>7. THEN GOTO 2030

2180 IF $K=7$ THEN GOTO 280

2190 CLEAR

2200 DISP USING " $4 /$ "

2210 DISP "WHICH PARAMETER NEEDS EDITING"

2220 DISP "( 1 THRU 5)?"

2230 DISP USING " $2 / "$

2240 FOR I=1 TO 4

2250 DISP USING $2260 ; I, ") ", O(K, I)$

2260 IMAGE $6 X, K, A, X, K$

2270 NEXT I

2280 DISP "

2290 DISP USING " $2 /$ "

2300 INPUT I

2310 IF I $<1$ OR L $>5$ THEN GOTO 2190

2320 IF L=5 THEN GOTO 2030

2330 DISP

2340 DISP $O(K, L)$

2350 DISP "INPUT NEW VALUE"

2360 INPUT $O(K, L)$

2370 CRT OFF \& CLEAR

2380 PRINT\# $1, K+6 ; A(K, 1), A(K, 2), A(K, 3), O(K, 1), O(K, 2), O(K, 3), O(K, 4)$

2390 READ\# $1, K+6 ; A(K, 1), A(K, 2), A(K, 3), O(K, 1), O(K, 2), O(K, 3), O(K, 4)$

2400 CRT ON

2410 GOTO 2190

2420 REM $\star \star \star \star \star \star \star \star \star *$ EXIT

2430 ASSIGN\# 1 TO *

2440 SUBEND 
100 SUB "ANALY" (X7)

110 REM

120 REM * COMPUTES TRUE MASS

130 REM USING FOUR I'S SERIES

140 REM

150 REM *DERIVED FROM FTN77

160 REM PROGRAM BY C I CARROLL

170 REM AND R S DAVIS.

180 REM

190 REM

200 REM

*WRITTEN BY J TAYLOR

FOR OWM $3 / 85$.

210 REM

220 OPTION BASE 1

230 REAL $A(7,3), B(6), C(4,2), D(4), E(4,4), F(4,6), G(6), H(6), O(6), P(4)$

240 REAL $Q(6), R(6), S(6), T(6), V(4,2), W(4), Y(4), Z(4), A 5, B 5, B 1, T I$

250 REAL V2,F5,M5,Ml,M2,M3,M4,Ol(5),Q3,Dl,S1,S2,S3,V1(6),X1,Yl,HI

260 REAL T2,R2,T4,Q1,Q2, Z1,T3,R3

270 INTEGER $\operatorname{LI}(7,4), \operatorname{L} 2(7,4), M(6,6), N, \operatorname{L} 3(7,4), \operatorname{L} 4(7,4), L(7,4)$

280 DIM H2\$[20], H3\$[8]

290 FOR $I=1$ TO 4

300 FOR $\mathrm{J}=1$ TO 7

$310 \operatorname{READ} \operatorname{Ll}(\mathrm{J}, \mathrm{I})$

320 NEXT J

330 NEXT I

340 FOR $I=1$ TO 4

350 FOR $\mathrm{J}=1$ TO 7

$360 \operatorname{READ}$ L2 $(J, I)$

370 NEXT J

380 NEXT I

390 FOR $I=1$ TO 4

400 FOR $\mathrm{J}=1$ TO 7

$410 \operatorname{READ~L3}(\mathrm{J}, \mathrm{I})$

420 NEXT J

430 NEXT I

440 FOR I=I TO 4

450 FOR $\mathrm{J}=1$ TO 7

$460 \operatorname{READ~L} 4$ (J,I)

470 NEXT J

480 NEXT I

490 DATA $0,0,0,0,0,0,4,-2,-1,-1,1,1,0,4$

500 DATA $-1,-2,-1,-1,0,1,4,-1,-1,-2,0,-1,-1,4$

510 DATA $2,1,1,-1,-1,0,4,-2,-1,-1,1,1,0,4$

520 DATA $0,-3,-1,-3,-1,2,4,0,-1,-3,-1,-3,-2,4$

530 DATA $3,3,2,0,-1,-1,4,-3,0,-1,3,2,-1,4$

540 DATA $0,-3,-1,-3,-1,2,4,0,0,-4,0,-4,-4,4$

550 DATA $1,1,1,0,0,0,1,-1,0,0,1,1,0,1$

560 DATA $0,-1,0,-1,0,1,1,0,0,-1,0,-1,-1,1$

570 FOR $I=1$ TO 6

580 FOR $J=1$ TO 6

$590 \operatorname{READ} M(J, I)$

600 NEXT J

610 NEXT I

620 DATA $4,-2,-2,2,2,0,-2,4,-2,-2,0,2,-2,-2,4,0,-2,-2$

630 DATA $2,-2,0,4,-2,2,2,0,-2,-2,4,-2,0,2,-2,2,-2,4$

640 FOR $I=1$ TO 4

650 FOR $\mathrm{J}=1$ TO 4

$660 \operatorname{READ} E(J, I)$

670 NEXT J

680 NEXT I

690 DATA $0, .5, .5, .5, .125, .125, .375, .375, .166666666667, .166666666667, .16666666666$ 
700 DATA $.333333333333, .1875, .1875, .1875, .1875$

$710 \quad F 5=3.78$

720 A5 $=3$

$730 \quad P(1)=4$

$740 \quad P(2)=8$

$750 \quad P(3)=12$

$760 \mathrm{P}(4)=4$

770 ON X7 GOTO $780,800,820$

780 ASSIGN\# 1 TO "A MAIN"

790 GOTO 840

800 ASSIGN\# I TO "B MAIN"

810 GOTO 840

820 ASSIGN\# I TO "C MAIN"

830 GOTO 840

840 READ\# 1,$1 ; \mathrm{N}, \mathrm{H} 2 \$, \mathrm{H} 3 \$$

850 READ\# 1,$2 ; \mathrm{Ml}, \mathrm{M} 2, \mathrm{~B} 5, \mathrm{~S} 3, \mathrm{~S} 2, \mathrm{Tl}, \mathrm{Bl}, \mathrm{HL}$

$860 \mathrm{M} 3=0$

$870 M 4=0$

880 FOR $I=1$ TO 4

890 READ\# $I, I+2 ; C(I, I), V(I, I), D(I), W(I), C(I, 2), V(I, 2)$

900 NEXT I

910 T2 $=0$

920 R2 $=0$

930 PRINT USING 940 ; H2\$,H3\$

940 IMAGE $30 \mathrm{X}, 20 \mathrm{~A}, 20 \mathrm{X}, 8 \mathrm{~A}, 3 /$

950 PRINT USING 960 ; "OBS 1 ", "OBS 2", OBS 3", "OBS 4" "MG/DV", "DRIFT"

960 IMAGE $5 X, K, 5 X, K, 5 X, K, 5 X, K, 7 X, K, 6 X, K, /$

970 FOR $I=I$ TO 6

980 READ\# $1, I+6 ; T(I), B(I), H(I), O I(I), O I(2), O I(3), O I(4)$

$9 \supseteq 0 \mathrm{~T}(I)=\mathrm{T}(I)+\mathrm{TI}$

$1000 \mathrm{~T} 2=\mathrm{T} 2+\mathrm{T}(\mathrm{I})$

$1010 \quad B(I)=B(I)+B I$

$1020 \mathrm{H}(I)=\mathrm{H}(I)+\mathrm{HI}$

$1030 \mathrm{VI}(I)=0$

$1040 R(I)=0$

$1050 \times 2=V I(I)$

$1060 \times 3=R(I)$

$1070 \times 4=T(I)$

$1080 \times 5=B(I)$

$1090 \times 6=\mathrm{H}(I)$

1100 CALL "SUBRHO" ( X4,X5,X6,X2,X3)

$2110 \mathrm{VI}(I)=\mathrm{X} 2$

$1120 \mathrm{R}(I)=X 3$

$1130 \mathrm{R} 2=\mathrm{R} 2+\mathrm{R}$ (I)

$1140 \mathrm{~T}(I)=\mathrm{T}(I)-20$

$1150 \mathrm{SI}=01(1)-01(4)+3 *(01(3)-01(2))$

$1160 S(I)=2 *(S 3-R(I) * S 2) / S I$

$1170 \mathrm{~A}(I, I)=(O I(I)-O I(2)-O I(3)+O I(4)) * S(I) / 2$

$1180 G(I)=(-0 I(I)+0 I(2)-0 I(3)+0 I(4)) / 2$

$1190 \mathrm{G}(I)=G(I) \star S(I)$

1200 PRINT USING $1210 ; 0 I(I), 01(2), 0 I(3), 0 I(4), S(I), G(I)$

1210 IMAGE $X, 4(M 4 D Z .3 D), 2 X, M 2 D Z .5 D, 2 X, M 2 D Z .3 D$

$1220 \mathrm{NEXT} I$

$+230 Q(1)=W(1)-W(2)$

$1240 Q(2)=W(1)-W(3)$

$1250 Q(3)=W(1)-W(4)$

$1260 Q(4)=W(2)-W(3)$

$1270 \quad Q(5)=W(2)-W(4)$

$1280 Q(6)=W(3)-W(4)$ 
1290 FOR $I=1$ TO 2

$1300 F(I, I)=V(I, I) *(I+C(I, I) * T(I))-V(2, I) *(I+C(2, I) * T(1))$

$1310 F(I, 2)=V(I, I) *(I+C(I, I) * T(2))-V(3, I) *(I+C(3, I) * T(2))$

$1320 F(I, 3)=V(I, I) *(I+C(I, I) * T(3))-V(4, I) *(I+C(4, I) * T(3))$

$1330 F(I, 4)=V(2, I) *(I+C(2, I) * T(4))-V(3, I) *(I+C(3, I) * T(4))$

$1340 F(I, 5)=V(2, I) *(I+C(2, I) * T(5))-V(4, I) *(I+C(4, I) * T(5))$

$1350 \quad F(I, 6)=V(3, I) *(I+C(3, I) * T(6))-V(4, I) *(I+C(4, I) * T(6))$

1360 NEXT I

1370 FOK $I=1$ TO 6

$1380 A(I, 2)=A(I, I)+R(I) *(F(I, I)+F(2, I))-Q(I)$

1390 NEXT I

$1400 \cdot A(7,2)=M I$

1410 IF $N=2$ THEN $A(7,2)=M 1+M 2$

$1420 A(1,3)=M 1-(A(1,2)+R(1) \star V(2,1) \star(1+C(2,1) \star T(1)))$

$1430 A(2,3)=M I-(A(2,2)+R(2) * V(3,1) *(1+C(3,1) * T(2)))$

$1440 A(3,3)=M 1-(A(3,2)+R(3) * V(4,1) *(1+C(4,1) * T(3)))$

$1450 A(4,3)=M 2-(A(4,2)+R(4) * V(3,1) *(1+C(3,1) * T(4)))$

$1460 A(5,3)=M 2-(A(5,2)+R(5) * V(4,1) *(1+C(4,1) * T(5)))$

$1470 A(6,3)=0$

1480 PRINT USING 1490

1490 IMAGE //

1500 PRINT USING 1510 ; "TEMP" "BARO" "HUM" "VAP" "RHO" "DV" "RHO*DV"

1510 IMAGE $6 \mathrm{X}, \mathrm{R}, 5 \mathrm{X}, \mathrm{K}, 5 \mathrm{X}, \mathrm{K}, 6 \mathrm{X}, \mathrm{R}, 6 \mathrm{X}, \mathrm{K}, 8 \mathrm{X}, \mathrm{K}, 7 \mathrm{X}, \mathrm{K}, /$

1520 FOR $I=1$ TO 6

$1530 \mathrm{~T} 4=\mathrm{T}(\mathrm{I})+20$

1540 V2=F(1,I)+F(2,I)

$1550 \mathrm{D} 1=\mathrm{R}(\mathrm{I}) * \mathrm{~V} 2$

1560 PRINT USING $1570 ; \mathrm{T} 4, \mathrm{~B}(\mathrm{I}), \mathrm{H}(\mathrm{I}), \mathrm{VI}(\mathrm{I}), \mathrm{R}(\mathrm{I}), \mathrm{V} 2, \mathrm{DI}$

1570 IMAGE 3X,M2DZ.2D,X,M4DZ.2D,M4DZ.1D,M3DZ.2D,X,M2DZ .4D,M4DZ.4D,X,M4DZ.3D

1580 NEXT I

1590 PRINT USING 1600

1600 IMAGE 2/

1610 PRINT USING 1620 ; "BAL DIFF","MASS IN AIR", "A" "DELTA"

1620 IMAGE $6 \mathrm{X}, \mathrm{K}, 5 \mathrm{X}, \mathrm{K}, 13 \mathrm{X}, \mathrm{K}, 12 \mathrm{X}, \mathrm{K}, /$

$1630 Q 3=0$

1640 FOR $I=1$ TO 6

$1650 \times 1=0$

1660 FOR $J=1$ TO 6

$1670 \times 1=X I+M(J, I) * A(J, 2)$

1680 NEXT J

$1690 \mathrm{O}(\mathrm{I})=\mathrm{X} 1 / 8$

$1700 Q 3=Q 3+O(I)^{\wedge} 2$

1710 PRINT USING $1720 ; A(I, I), A(I, 3), A(I, 2), O(I)$

1720 IMAGE $5 X, M 2 D Z$. 3D, 2X,M9DZ . 3D, X, M9DZ .3D, 4X,M5DZ.3D

1730 NEXT I

1740 PRINT USING 1750

1750 IMAGE $2 /$

1760 PRINT USING 1770 ; "DENSITY","TM","SD", "V AT 20"

1770 IMAGE $7 \mathrm{X}, \mathrm{K}, 9 \mathrm{X}, \mathrm{K}, 17 \mathrm{X}, \mathrm{K}, 10 \mathrm{X}, \mathrm{K}, 1$

1780 FOR $I=1$ TO 4

$1790 Y 1=0$

1800 FOR J=1 TO 7

1810 IF $N=I$ THEN $L(J, I)=L I(J, I)$

1820 IF $N=2$ THEN $L(J, I)=L 2(J, I)$

$1830 Y I=Y I+L(J, I) * A(J, 2)$

1840 NEXT J

$1850 \mathrm{Y}(\mathrm{I})=\mathrm{Y} 1 / \mathrm{P}(\mathrm{N})$

$1860 \mathrm{~V}(\mathrm{I}, I)=\mathrm{Y}(\mathrm{I}) \star .001 / \mathrm{D}(\mathrm{I})$

1870 IF $E(I, N)=0$ THEN 1910

$1880 Z(I)=S Q R\left(B 5^{\wedge} 2 \star E(I, N)\right)$ 


\section{GOTO 1920}

$1910 Z(I)=0$

1920 PRINT USING $1930 ; D(I), Y(I), Z(I), V(I, I)$

1930 IMAGE $4 \mathrm{X}, \mathrm{M} 2 \mathrm{DZ}: 5 \mathrm{D}, \mathrm{X}, \mathrm{M} 9 \mathrm{DZ} .3 \mathrm{D}, \mathrm{X}, \mathrm{M} 9 \mathrm{DZ} .3 \mathrm{D}, 3 \mathrm{X}, \mathrm{M} 5 \mathrm{DZ} .5 \mathrm{D}$

1940 NEXT I

$1950 Q 1=S Q R(Q 3 / A 5)$

$1960 \mathrm{Q} 2=\mathrm{Q} 3 / \mathrm{A} 5 / \mathrm{B} 5^{\wedge} 2$

1970 PRINT USING 1980

1980 IMAGE $2 /$

1990 PRINT USING 2000 ; "ACC SD"."OBS SD", "F RATIO", "F TEST", "DF"

2000 IMAGE $7 \mathrm{X}, \mathrm{K}, 8 \mathrm{X}, \mathrm{R}, 6 \mathrm{X}, \mathrm{K}, 6 \mathrm{X}, \mathrm{K}, 9 \mathrm{X}, \mathrm{R}, 1$

2010 PRINT.USING $2020 ; \mathrm{B} 5, \mathrm{Q} 1, \mathrm{Q} 2, \mathrm{~F} 5, \mathrm{~A} 5$

2020 IMAGE 2(M7DZ.3D,X),3X,M3DZ.3D,3X,M4DZ .2D, 10X,D

2030 IF ABS $(Q 2)<=3.78$ THEN GOTO 2050

1040 PRINT $n \star \star \star \star \star$ WARNING $\star \star \star \star \star \star$ F RATIO IS NOT IN CONTROL."

!050 PRINT USING 1980

.060 IF $\mathrm{N}=1$ THEN $M 5=\mathrm{M} 2$

070 IF $N=2$ THEN $M 5=M 1-M 2$

080 IF $N=1$ THEN $Y 1=Y(2)$

090 IF $N=2$ THEN $Y I=Y(1)-Y(2)$

095 IF $N=2$ THEN $Z(2)=S Q R\left(B 5^{\wedge} 2 * .5\right)$

$! 100 \mathrm{Zl}=(\mathrm{Y} 1-\mathrm{M} 5) / \mathrm{Z}(2)$

:110 $\mathrm{T} 3=\mathrm{T} 2 / 6$

! $120 \mathrm{R} 3=\mathrm{R} 2 / 6$

!130 PRINT USING 2140 ; "ACC DIFF","OBS DIFF","T TEST", "MEAN TEMP", "MEAN RHO"

:I 40 IMAGE $7 \mathrm{X}, \mathrm{K}, 6 \mathrm{X} ; \mathrm{K}, 7 \mathrm{X}, \mathrm{K}, 4 \mathrm{X}, \mathrm{K}, 4 \mathrm{X}, \mathrm{K}, /$

:I50 PRINT USING $2160 ; \mathrm{M} 5, \mathrm{YI}, \mathrm{ZI}, \mathrm{T} 3, \mathrm{R} 3$

!I60 IMAGE $3 \mathrm{X}, 2(\mathrm{M} 6 \mathrm{DZ} .3 \mathrm{D}, 2 \mathrm{X}), \mathrm{X}, \mathrm{M} 4 \mathrm{DZ} .3 \mathrm{D}, 3 \mathrm{X}, \mathrm{M} 3 \mathrm{DZ} .2 \mathrm{D}, 3 \mathrm{X}, \mathrm{M} 3 \mathrm{DZ} .4 \mathrm{D}$

!170 IF ABS $(Z I)<=3$ THEN GOTO 2190

! 180 PRINT $n \star \star \star \star \star$ WARNING $\star \star \star \star \star$ T TEST IS NOT IN CONTROL."

!I 90 ASSIGN\# I TO *

$: 200$ SUBEND 


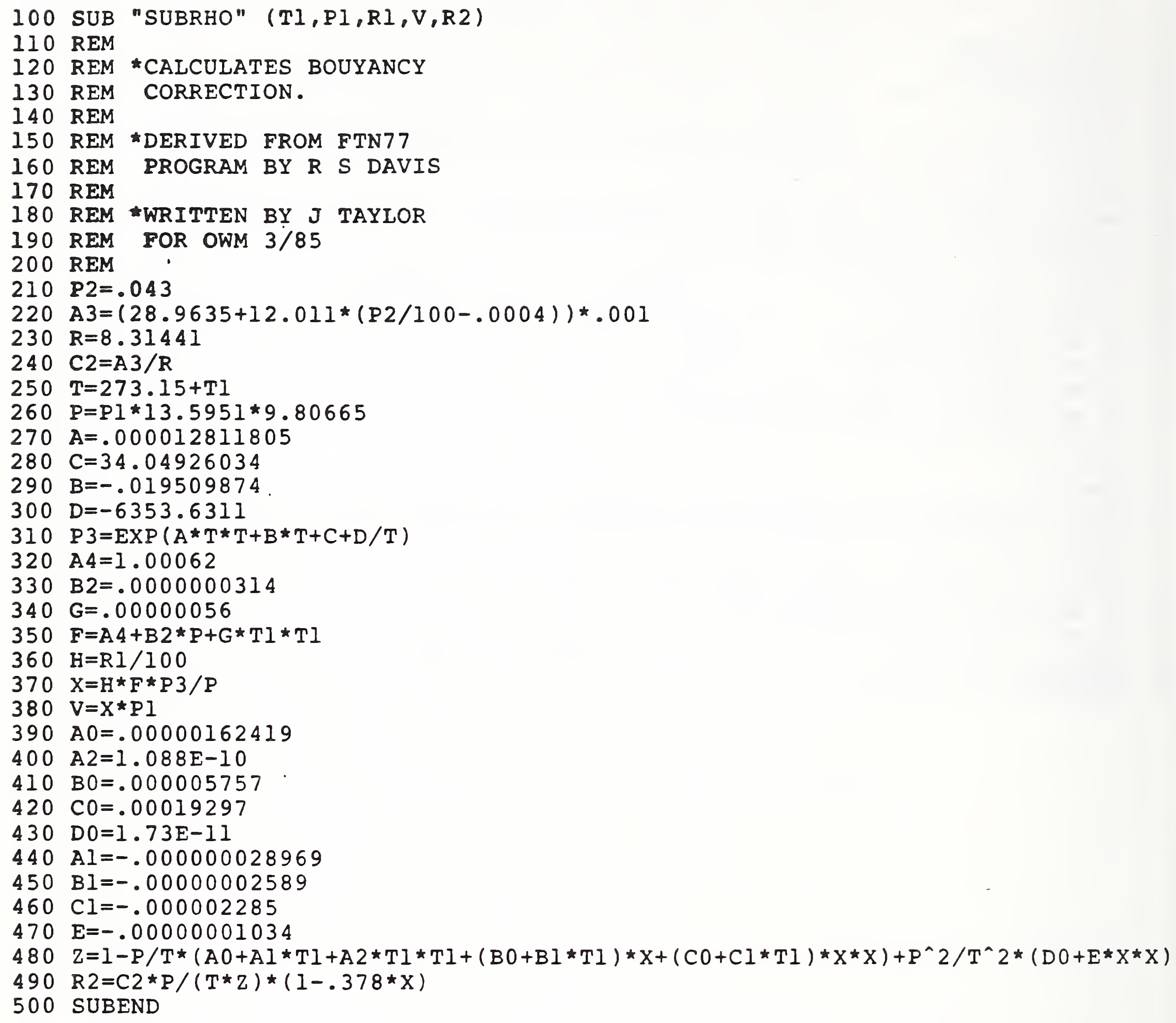




\section{REM PROGRAM "TRANSD"}

110 REM

120 REM *TRANSFERS DATA FILE

130 REM FROM AN OLD TAPE TO

140 REM A NEW TAPE CARTRIDGE.

150 REM

160 REM *WRITTEN BY J TAYLOR

170 REM FOR OWM $3 / 85$.

180 REM

190 OPTION BASE 1

200 DISP "INPUT NAME OF THE DATA FILE."

210 INPOT AS

220 ASSIGN\# 1 TO A\$

230 DIM B2\$[20],H3\$[8],A(11),B(11),C(11),D(11),E(1]),F(11), G(11),H(11)

240 INTEGER $\mathrm{N}$

250 READ\# 1,$1 ; \mathrm{N}, \mathrm{H} 2 \$, \mathrm{H} 3 \$$

260 READ\# 1,$2 ; A(1), B(1), C(1), D(1), E(I), F(1), G(1), H(I)$

270 FOR $I=1$ TO 4

280 READ\# $1, I+2 ; A(I+I), B(I+1), C(I+I), D(I+I), E(I+I), F(I+I)$

290 NEXT I

300 FOR $I=1$ TO 6

310 READ\# $1, I+6 ; A(I+5), B(I+5), C(I+5), D(I+5), E(I+5), F(I+5), G(I+5)$

320 NEXT I

330 ASSIGN\# I TO *.

340 CLEAR

350 DISP

360 DISP

370 DISP

380 DISP

390 DISP " 1)REMOVE OLD TAPE."

400 DISP

410 DISP " 2) INSERT NEW TAPE."

420 DISP

430 DISP " 3)PURGE DATA FILE IN NEW"

440 DISP "

TAPE, IF NECESSARY."

450 DISP

460 DISP " 4)RESUME BY PRESSING CONT."

470 PAUSE

480 CREATE A\$, 12,80

490 ASSIGN\# I TO AS

500 PRINT\# 1,$1 ; \mathrm{N}, \mathrm{H} 2 \$, \mathrm{H} 3 \$$

510 PRINT\# $I, 2 ; A(I), B(I), C(I), D(I), E(I), F(I), G(I), H(I)$

520 FOR I=1 TO 4

530 PRINT\# $1, I+2 ; A(I+1), B(I+1), C(I+1), D(I+1), E(I+1), F(I+1)$

540 NEXT I

550 FOR I=1 TO 6

560 PRINT\# $1, I+6 ; A(I+5), B(I+5), C(I+5), D(I+5), E(I+5), F(I+5), G(I+5)$

570 NEXT I

580 ASSIGN\# I TO *

590 CLEAR

$6 C ? \mathrm{CAT}$

610 END 
Appendix III.

Once a laboratory has recorded a complete set of data onto the tape cartridge an analysis of this information can begin and the 80-column printer will automatically generate a single page of tabulated results followed by a one-half page printout of the information stored in the data file. A sample of this output is shown in table 1 using data stored in one of the three data files, table 2. The assigned true mass values, TM, of each kilogram are located in the fourth row, second column of the printout. Where the first two of four values in this group correspond to assigned true mass values of the laboratory standards, and the third and fourth values in this group are the true mass values assigned to the "unknown" artifacts (A1-S2, R2-H2, or A1-TE).

The following is a brief description of each quality found in this report:

OBS (x) - Refers to each of the four balance observations of the double substitution weighing. Observations are usually read in milligrams; however, the NIST balance with its servo generates values in volts. The nature of substitution weighing with a sensitivity weight is that the observations may be of an arbitrary scale but in the data reduction the proper unit is established.

MG/DV - The value assigned to the balance optical scale divisions from weighing a sensitivity weight.

DRIFT - Linear shift (mg) between balance observations.

TEMP - Average temperature $\left({ }^{\circ} \mathrm{C}\right)$ obtained from automatic readings taken before and after a double substitution weighing.

BARO - Average barometric pressure ( $\mathrm{mm} \mathrm{Hg}$ ) obtained from automatic readings taken before and after a double substitution weighing.

HUM - Average relative humidity ( $\delta$ ) obtained from automatic readings taken before and after a double substitution weighing.

VAP - Vapor pressure (mm Hg) of water.

RHO - Computed air density $\left(\mathrm{mg} / \mathrm{cm}^{3}\right)$ derived by subprogram SUBRHO. This calculation is based on the work of Jones [5].

DV - Difference in volume $\left(\mathrm{cm}^{3}\right)$ between kilograms compared in the double substitution weighing.

RHO*DV - Mass (mg) correction that arises from the difference in buoyant forces acting upon the two kilograms.

BAL DIFF - Difference in the observed readings (mg) between two kilograms. This mass difference includes any tare weight that may be added to the kilograms, but corrections due to the effects of air buoyancy are not applied to this group of weights. 
MASS IN AIR - Assigned mass (mg) without buoyancy corrections, of the "unknown" kilogram or the check standard with respect to the laboratory standard used in the double substitution weighing.

A - Difference in the observed readings ( $\mathrm{mg}$ ) between two kilograms. In this calculation the mass of all added tare weights have been removed and the appropriate air buoyancy correction applied to each artifact.

DELTA - Residuals ( $\mathrm{mg}$ ) obtained when fitting the data using the method of least squares.

DENSITY - Density $\left(\mathrm{g} / \mathrm{cm}^{3}\right)$ of each kilogram based on hydrostatic measurement.

TM - The mass (mg) of each kilogram.

SD - The measurement estimate of standard deviation (mg) for each kilogram.

V AT 20 - Volume $\left(\mathrm{cm}^{3}\right)$ of each kilogram at 20 degrees Celsius. This group of values is derived from the computed true mass values and densities of the kilograms.

ACC SD - Accepted standard deviation (mg) of the balance.

OBS SD - The observed estimate of standard deviation ( $\mathrm{mg}$ ) of the balance as determined for each weighing series by the least squares adjustments.

F RATIO - Examines the precision of the weighing series using the equation

$$
\text { F ratio }=\frac{(\mathrm{OBS} S \mathrm{SD})^{2}}{(\mathrm{ACC} S \mathrm{~S})^{2}}
$$

where,

OBS SD = observed standard deviation of the balance, and ACC SD = accepted standard deviation of the balance.

F TEST - Has a constant value equal to 3.78 (the critical value) and is compared to the weighing series F ratio. A warning is printed if the absolute value of $F$ ratio is greater than the $F$ test. The value 3.78 is based on the number of degrees of freedom in OBS SD (3) and ACC SD ( $\infty)$.

DF - Degrees of freedom.

ACC DIFF - The accepted difference in mass (mg) of the two laboratory standards.

OBS DIFF - The measured difference in mass (mg) of the two laboratory standards. 
t-TEST - Examines the difference in mass between the two standards using the equations below. However, the equation used here ignores the random uncertainty associated with the standards. In a calibration laboratory, the random uncertainty is small due to averaging over a large pool of data.

$$
\text { t-test }=\frac{(\text { ACC DIFF })-(O B S D I F F)}{S}
$$

and

$$
S=\left[(\operatorname{ACC} S D)^{2} / 2\right]^{1 / 2}
$$

where,

ACC DIFF = accepted difference between the two laboratory standards, OBS DIFF = observed difference between the two laboratory standards, and

ACC SD = accepted standard deviation of the balance.

MEAN TEMP - Average temperature $\left({ }^{\circ} \mathrm{C}\right)$ of the six double substitutions.

MEAN RHO - Average air density $\left(\mathrm{mg} / \mathrm{cm}^{3}\right)$ of the six double substitutions. 
Table 1. Printout of results derived from data file in table 2. SAMPLE DATA

$2 / 5 / 86$

$\begin{array}{lllllr}\text { OBS } 1 & \text { OBS } 2 & \text { OBS } 3 & \text { OBS } 4 & \text { MG/DV } & \text { DRIFT } \\ 22.600 & 24.270 & 43.900 & 42.440 & 1.02418 & 0.108 \\ 22.850 & 21.080 & 40.690 & 42.560 & 1.02235 & 0.051 \\ 22.980 & 21.850 & 41.460 & 42.730 & 1.02339 & 0.072 \\ 24.660 & 21.350 & 40.960 & 44.300 & 1.02052 & 0.015 \\ 24.680 & 21.900 & 41.560 & 44.280 & 1.01560 & -0.030 \\ 21.480 & 21.940 & 41.520 & 41.120 & 1.02287 & 0.031\end{array}$

$\begin{array}{rrrrrrr}\text { TEMP } & \text { BARO } & \text { HUM } & \text { VAP } & \text { RHO } & \text { DV } & \text { RHO*DV } \\ . & & & & & & \\ 23.66 & 743.43 & 38.8 & 8.56 & 1.1586 & -0.2398 & -0.278 \\ 23.67 & 743.44 & 38.8 & 8.55 & 1.1587 & -232.1703 & -269.005 \\ 23.67 & 743.47 & 38.8 & 8.56 & 1.1587 & 67.3729 & 78.063 \\ 23.67 & 743.48 & 38.8 & 8.56 & 1.1587 & -231.9306 & -268.730 \\ 23.68 & 743.47 & 38.8 & 8.56 & 1.1586 & 67.6128 & 78.339 \\ 23.68 & 743.48 & 38.8 & 8.57 & 1.1587 & 299.5435 & 347.067\end{array}$

BAL DIF
-1.603
1.861
1.228
3.393
2.793
-0.440

DENSITY

$$
\begin{array}{r}
7.85030 \\
7.83556 \\
2.78252 \\
16.65790
\end{array}
$$

ACC SD

$$
0.050
$$

ACC DIFF

$-1.828$
MASS IN AIR

$$
\begin{array}{r}
999865.689 \\
999862.223 \\
999857.860 \\
999862.238 \\
999857.848 \\
0.000
\end{array}
$$

TM

$$
\begin{array}{r}
1000011.691 \\
1000013.543 \\
1000278.901 \\
999927.366
\end{array}
$$

A

$$
-1.881
$$$$
-267.144
$$$$
84.287
$$$$
-265.337
$$

86.128

351.623

SD

$$
\begin{aligned}
& 0.018 \\
& 0.018 \\
& 0.031 \\
& 0.031
\end{aligned}
$$

DELTA

$-0.028$

0.067

$-0.038$

0.021

$-0.049$

0.088

V AT 20

$$
\begin{array}{r}
127.38516 \\
127.62503 \\
359.48669 \\
60.02722
\end{array}
$$

$\begin{array}{lrr}\text { F RATIO } & \text { F TEST } & \text { DF } \\ 2.306 & 3.78 & 3\end{array}$

T TEST MEAN TEMP MEAN RHO

$\begin{array}{ll}-0.688 & 23.67\end{array}$

1.1587 
Table 2. Printout of data file used to generate results in table 9 .

$* * * *$ MAIN DATA FILE $* * * * *$

2

SAMPLE DATA

$2 / 5 / 86$

$1000011.7031000013 .531 \quad 0.050 \quad 20.00570 \quad 0.00741 \quad 0.000 \quad 0.000 \quad 0.000$

$\begin{array}{rrrrrr}0.000045 & 127.3852 & 7.85030 & 0.000000 & 0.000000 & 0.00000 \\ 0.000045 & 127.6250 & 7.83556 & 0.000000 & 0.000000 & 0.00000 \\ 0.000069 & 359.4856 & 2.78252 & 0.000000 & 0.000000 & 0.00000 \\ 0.000020 & 60.0271 & 16.65790 & 4.995900 & 0.000069 & 0.00185\end{array}$

$\begin{array}{lllllll}23.663 & 743.428 & 38.847 & 22.600 & 24.270 & 43.900 & 42.440 \\ 23.666 & 743.444 & 38.792 & 22.850 & 21.080 & 40.690 & 42.560 \\ 23.670 & 743.467 & 38.846 & 22.980 & 21.850 & 41.460 & 42.730 \\ 23.673 & 743.476 & 38.847 & 24.660 & 21.350 & 40.960 & 44.300 \\ 23.676 & 743.469 & 38.846 & 24.680 & 21.900 & 41.560 & 44.280 \\ 23.679 & 743.484 & 38.847 & 21.480 & 21.940 & 41.520 & 41.120\end{array}$


NBS-114A (REV. 2.8C)

U.S. DEPT. OF COMM.

BIBLIOGRAPHIC DATA

SHEET (See instructions)

4. TITLE AND SUBTITLE

An Investigation of a User-Operated Mass Calibration Package

5. AUTHOR(S)

Randall M. Schoonover and James E. Taylor

6. PERFORMING ORGANIZATION (If joint or other than NBS, see instructions)

7. Contract/Grant No.

NATIONAL BUREAU OF STANDARDS

U.S. DEPARTMENT OF COMMERCE

GAITHERSBURG, MD 20899

9. SPONSORING ORGANIZATION NAME AND COMPLETE ADDRESS (Street。 City, State, ZIP)

10. SUPPLEMENTARY NOTES

Document describes a computer program: SF-185, FIPS Software Summary, is attached.

11. ABSTRACT (A 200-word or less foctual summary of most significant information. If document includes a significant bibliogrophy or literoture survey. mention it here)

Reported here are the results of two round-robin mass measurement programs. The first round-robin elucidated the many technical problems that required solutions before successful mass calibrations could be performed in all of the participant laboratories. This report details the technical innovations i.e., thermal conditioning of the kilogram weights, balance servo control, automatic data acquisition, the measurement of some air density parameters, computer software, and presents the results. Te believe the results clearly indicate we could, in the future, successfully calibrate mass standards at locations remote from the NBS laboratory while maintaining the rigor necessary for certification.

12. KEY WORDS (Six to twelve entries; alphobetical order; copitolize only proper nomes; ond seporote key words by semicolons) air buoyancy; balance servo; computer-control; mass; software; surface-effects; temperature control; thermal-conditioning; thermal-effects; weighing

13. AVAILABILITY

EX Unlimited

$\square$ For Official Distribution. Do Not Release to NTIS

Order From Superintendent of Documents, U.S. Government Printing Office, Washington. D.C. 20402.

Q] Order From National Technical Information Service (NTIS), Springfield, VA. 2216I
14. NO. OF PRINTED PAGES

64

15. Price

$\$ 13.95$ 

